Sharif University of Technology
Scientia Iranica
Transactions E: Industrial Engineering
hCIENTIA

\title{
Multi-objective open location-routing model for relief distribution networks with split delivery and multi-mode transportation under uncertainty
}

\author{
D. Veysmoradi ${ }^{a}$, B. Vahdani ${ }^{a, *}$, M. Farhadi Sartangi ${ }^{b}$, and S.M. Mousavi ${ }^{\mathrm{c}}$ \\ a. Department of Industrial Engineering, Faculty of Industrial and Mechanical Engineering, Qazvin Branch, Islamic Azad \\ University, Qazvin, P.O. Box 3419759811 , Iran. \\ b. Department of Industrial Engineering, Payam Noor University (PNU), Tehran, P.O. Box 19395-3697, Iran. \\ c. Department of Industrial Engineering, Faculty of Engineering, Shahed University, Tehran, P.O. Box 18155/159, Tehran, Iran.
}

Received 3 April 2016; received in revised form 23 June 2017; accepted 23 October 2017
KEYWORDS
Emergency logistics;
Relief distribution;
Location;
Routing;
Split delivery;
Multi-objective
programming;
Robust optimization.

\begin{abstract}
In this study, the response phase of the management of natural disasters is investigated. One of the important issues in this phase is determining the distribution areas and timely distributing relief to affected areas in which transportation routing is of critical importance. In the event of disasters, especially flood and earthquake, terrestrial transportation is not fairly easy due to the damage to many infrastructures. For this reason, we propose that delivering relief from the distribution areas to disaster stricken places should be done by terrestrial and aerial transportation modes, simultaneously, to increase route reliability and reduce travel time. In this study, for relief allocation after earthquake, we offer a mixed-integer nonlinear open location-routing model in uncertain condition. This model includes several contradictory objectives and a variety of factors such as travel time, total costs, and reliability. In order to solve this model, a hybrid solution by combining robust optimization and fuzzy multi-objective programming has been used. The performance and effectiveness of the offered model and solution approach have been investigated through a case study of earthquake in East Azerbaijan, Iran. Our computational results show that the solution we have offered for real problems is effective.

(C) 2018 Sharif University of Technology. All rights reserved.
\end{abstract}

\section{Introduction}

Since natural catastrophe, earthquakes, torrents, and tornados are unpredicted, they can cause severe and lasting damage to countries. Of all events, earthquake is the major reason for deaths. Examples from previous years include the deaths of 40 thousand people in 2003 in Bam earthquake in Iran [1], 70 thousand in the 2007 Sichuan earthquake [2], and 23,000 thousand in the 2010 Haiti earthquake [3].

\footnotetext{
*. Corresponding author

E-mail address: b.vahdani@gmail.com (B.Vahdani).
}

doi: $10.24200 /$ sci. 2017.4572
As in the time of earthquake or any natural disasters, infrastructures would be ruined, the supplies and logistics services would be highly requested. Processes in emergency after earthquake should be planned in such a way that they can respond to the needs of causalities as fast as possible. The reason is that immediate distribution of emergency supplies can play a key role in reducing the damage and disastrous events. In the meantime, one of the required strategic decisions in this regard is determining the place of distribution centers. The places which will be selected to serve as warehouse need to meet some prerequisites such as physical and economic accessibility, and non-violation of local and state constraints. When the suitable places of distribution are identified, a group of places, 
which can address the limitations of the system and are in the best conditions, are chosen. The objective of the problem may include items such as minimizing the cost, maximizing demand covering, minimizing the maximum travelling time, etc., or a combination of them. In addition to the above-mentioned factors, the efficiency of the system depends on other factors.

In this regard, it is more important to know how the transport fleet is organized and managed as it positively contributes to efficacy of the distribution chain [4]. Therefore, the decision for selecting Distribution Centers (DC) depends on the number and means of transportations assigned to each DC, the delivery route to disaster areas, and allocation of disaster areas to the established centers [5].

The properties that make the problem closer to actual emergency condition are as follows:

1. At the post-earthquake time, vehicles stay in the last node of their routes and do not go back to DCs until another order is specified; for this reason, each region receiving the relief could be considered as a new distribution center [6]. Open Location-Routing Problem (OLRP) is an emerging issue in the literature. The first study to investigate the issue was the research conducted by Qiu and Xumei [7];

2. In spite of a great demand for relief in the earthquake stricken areas after earthquake, each of the areas receives service more than once, because the capacity of the vehicles is quite limited [8]. This method has been referred to as split delivery. In their experimental research, Archeti et al. [9] investigated the routing of transportation vehicle and focused on the split-delivery of the demand, and showed that when the demand means of the customers fell between 50 to $75 \%$ of the capacity of the vehicles and the variance was smaller, better results in terms of profit and savings would be achieved;

3. One of main concerns associated with earthquakes, which differentiates them from terrorist attack or other natural catastrophes, is that aftershocks can put the lives of the aid workers in jeopardy. Therefore, preparation for the aftermaths of earthquake is necessary. One of the aftermaths of earthquake is destruction of transport networks between disaster areas, highways, bridges, and tunnels. In this case, we can conceptualize reliability as the likelihood of traveling through the network among disaster areas in the postearthquake time. In this case, aid distribution in disaster increases with high reliability, which can not only support the rescue team but also guarantee timely delivery of necessary facilities to them [10];

4. In the event of a disaster, especially earthquake, either a lot of infrastructures for transportation become unusable or many disaster areas are remote and difficult to reach, or unavailable by land. In order to provide relief to these areas, air transportation network can be used, which can increase the reliability of the route and timely delivery of relief supplies to the regions;

5. A kind of uncertainty is associated with disorders. This type of uncertainty results from unexpected disasters such as torrent, earthquakes, tornados, financial crises, and terrorist attacks. Dynamic and intricate nature of disaster relief chain imposes a high level of uncertainty in decision-making for logistics planning of relief and affects the functionality of the chain. Important parameters such as the demand rate as well as supply in the damaged areas, and the cost and time of transfer of goods may be inaccurate in times of disaster because of incompleteness or unavailability of the data required. As a result, addressing uncertainties can help to have a right strategic, tactical, and operational decision [11].

Given the issues outlined, in this study, attempts are made to provide a multi-objective model under uncertainty about the locations of DCs, allocate disaster stricken regions and transportation vehicles to DCs, and design the routes from DCs to disaster stricken regions by taking into account the split delivery of the demand. Also, in this study, the relief guidance from DCs to disaster stricken regions is considered by terrestrial and aerial transportation networks, simultaneously, and the route for all transportation vehicles is considered to be open. The purposes of the model are (1) minimizing the fixed costs to establish DCs and the vehicle travelling cost, (2) minimizing the maximum travel time of the vehicle route, and (3) maximizing the minimum reliability of the route for all service vehicles in the process. In addition, a hybrid solution is proposed for better analysis of uncertainties by combining robust optimization and fuzzy multiobjective programming. Finally, the efficiency of the model is shown through a case study of the earthquake in East Azarbaijan, Iran.

The paper is organized as follows: in Section 2, we will review the literature on relief logistics and LRP. Section 3 includes the statement of the problem and the proposed model. The proposed solution is presented in Section 4. Computational results and the case study to validate the model are presented in Section 5. In Section 6, we will make conclusions and recommendations for future research.

\section{Literature review}

So far, the location of DCs and routing of transportation vehicles have generally been studied individually 
for logistics in the state of emergency; however, they heavily depend on each other. There is a dearth of research on the design of mathematical models and solution approaches to the integration of the location and routing in the state of earthquake.

Akkihal [12] proposed a model for location crisis management centers to manage the aid goods. His study was only limited to non-edible supplies such as water refining systems, medical resources, tents, and information tools, because such goods are necessary when the disaster starts. The study determined the optimal location of the storage of non-consumable goods for the purpose of distance minimization. In other words, the average interval for anyone who was at risk to the nearest facility was minimized by taking into account the limitations related to the lack of resources.

Tzeng et al. [13] proposed a multi-criteria decision model for the distribution of emergency supplies to affected regions. The model involved different factors such as the expenses, response time, and customers' satisfaction and the problem was solved by using fuzzy multi-objective programming. Rajagopalan et al. [14] suggested a multi-period location-covering model to send an ambulance in an emergency case. The purpose of the model was to enhance urgent medical care service to respond to the needs at the time of the event. However, vehicle routing was not considered. In another study carried out by Balcik and Beamon [15], the radius of coverage for humanitarian relief was examined. The proposed model considered the financial limitations before and after the natural disaster. Moreover, they defined upper and lower limits for response time to the supply demands from each center. They also showed that aid time should be shorter than this time.

Vitoriano et al. [16] proposed a multi-criteria optimization model founded on cost, time, and priority for the delivery of humanitarian assistance. Ozdamar [17] provided an effective programming system for the use of helicopter in disaster relief operations, which was a new model and a route management approach. The transfer of necessary items such as blood, medicine, etc. to damaged areas as well as evacuation of the damaged people from these locations was among the duties considered for the helicopter. The purpose of this model was to minimize the time needed to perfect the mission of transportation, including flight time as well as the time for unloading the equipment and boarding the injured. Ozdamar and Demir [18] proposed a hierarchical clustering method and routing to facilitate relief distribution in a large scale. To this end, they employed an algorithm to organize the demand nodes into smaller categories. Then, they offered an optimal solution to vehicle routing. Bozorgi Amiri et al. [11] proposed a multi-objective robust stochastic programming for aid logistics under uncertainty. The study highlighted demand, supply, and cost as well as transportations as uncertain factors and measured them.

Wang et al. [10] developed a multi-purpose relief distribution model for earthquake stricken zones. They solved open location-routing problem for relief after the earthquake. The disaster network in their research consisted of DCs and the disaster stricken regions. In the intended model, only the disaster areas that were accessible via ground transportation were considered and those which needed helicopter or other vehicles were not considered at all. In another study, Talarico et al. [19] formulated a routing problem for ambulance at the time of natural catastrophe. In their study, ambulances were used to carry not only health care personnel but also patients. The patients fell into two groups: Those who had fewer injuries and could directly get aid, and those who were seriously injured and should be transferred to hospital. Because ambulances represent scarce resources in disaster conditions, efficient use of them is very important. Two mathematical formulae were used to obtain the route plans to minimize the total relief time. In the following, categorization of the existing researches is provided in Table 1 in order to show the research gap and innovations of this article.

Regarding Table 1, it can be seen that this research has favorable innovations compared to the research background. Yet, it can be stated that it is based on the study done by Wang et al. [10], to make the innovation of this research clearer. In the mentioned research, the researchers provided the location-routing model for aid distribution after the crisis in a definite state. However, the changing and multi-faceted nature of disaster chain could cause a high level of uncertainty in the decision associated with logistic planning. Also, only ground transportation was used for rescue in their model. A point that should be noted here is that when a disaster occurs, transport infrastructures are often unreliable for rescue supplies. It is why in this research, we try to remove this dependency by concentrating on the use of air carriers in addition to ground transportation. According to the descriptions provided, in this study, the open locationrouting model is developed considering different transportation networks (ground and air); also, the robust optimization method provided by Ben Tal et al. [29] is applied to deal with uncertainties in some parameters of the model. The fuzzy multi-objective programming proposed by Torabi and Hassini [30] is used for solving the multi-objective model.

\section{Problem definition}

In this study, a relief distribution network is intended after earthquakes. Distribution network structure is depicted in Figure 1. In this study, aid distribution includes the location of delivery centers, vehicle rout- 
Table 1. Categories of research on the relief chain.

\begin{tabular}{|c|c|c|c|c|c|c|c|c|c|c|}
\hline Ref. & Location & Routing & $\begin{array}{c}\text { Split } \\
\text { delivery }\end{array}$ & $\begin{array}{c}\text { Single- } \\
\text { objective }\end{array}$ & $\begin{array}{c}\text { Multi- } \\
\text { objective }\end{array}$ & Certain & Uncertain & $\begin{array}{c}\text { Single } \\
\text { transport }\end{array}$ & $\begin{array}{c}\text { Multiple } \\
\text { transport }\end{array}$ & $\begin{array}{l}\text { Case } \\
\text { study }\end{array}$ \\
\hline$[20]$ & $\sqrt{ }$ & $\sqrt{ }$ & - & $\sqrt{ }$ & - & $\sqrt{ }$ & - & $\sqrt{ }$ & - & - \\
\hline$[21]$ & - & $\sqrt{ }$ & - & - & $\sqrt{ }$ & $\sqrt{ }$ & - & - & $\sqrt{ }$ & $\sqrt{ }$ \\
\hline$[22]$ & $\sqrt{ }$ & $\sqrt{ }$ & - & $\sqrt{ }$ & - & $\sqrt{ }$ & - & - & $\sqrt{ }$ & - \\
\hline [23] & - & $\sqrt{ }$ & $\sqrt{ }$ & $\sqrt{ }$ & - & $\sqrt{ }$ & - & $\sqrt{ }$ & - & - \\
\hline$[24]$ & $\sqrt{ }$ & $\sqrt{ }$ & - & $\sqrt{ }$ & - & $\sqrt{ }$ & - & $\sqrt{ }$ & - & - \\
\hline$[25]$ & - & $\sqrt{ }$ & - & - & $\sqrt{ }$ & - & $\sqrt{ }$ & - & $\sqrt{ }$ & - \\
\hline$[26]$ & $\sqrt{ }$ & $\sqrt{ }$ & - & - & $\sqrt{ }$ & $\sqrt{ }$ & - & $\sqrt{ }$ & - & - \\
\hline$[10]$ & $\sqrt{ }$ & $\sqrt{ }$ & $\sqrt{ }$ & - & $\sqrt{ }$ & $\sqrt{ }$ & - & $\sqrt{ }$ & - & $\sqrt{ }$ \\
\hline$[27]$ & $\sqrt{ }$ & $\sqrt{ }$ & - & - & $\sqrt{ }$ & - & $\sqrt{ }$ & $\sqrt{ }$ & - & - \\
\hline$[28]$ & $\sqrt{ }$ & - & - & - & $\sqrt{ }$ & - & $\sqrt{ }$ & - & - & $\sqrt{ }$ \\
\hline$[8]$ & $\sqrt{ }$ & $\sqrt{ }$ & $\sqrt{ }$ & - & $\sqrt{ }$ & - & $\sqrt{ }$ & $\sqrt{ }$ & - & - \\
\hline $\begin{array}{l}\text { Present } \\
\text { research }\end{array}$ & $\sqrt{ }$ & $\sqrt{ }$ & $\sqrt{ }$ & - & $\sqrt{ }$ & - & $\sqrt{ }$ & - & $\sqrt{ }$ & $\sqrt{ }$ \\
\hline
\end{tabular}

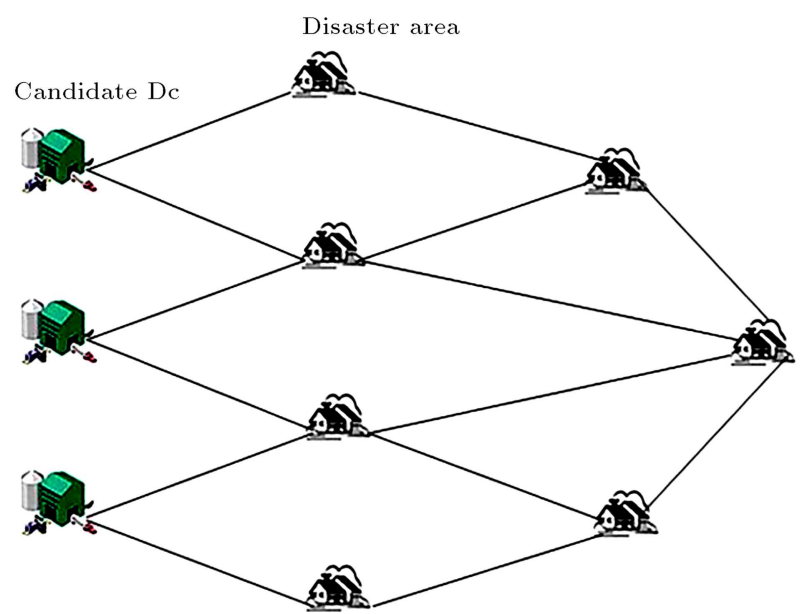

Figure 1. Network for OLRP in emergency logistics.

ing, and time programming after the earthquake. We offer a multi-purpose open location-routing problem with split delivery of demand. Because, in the event of disasters, especially flood and earthquake, terrestrial transportation is not that much easy due to the damage to many infrastructures. In this study, the aid by DCs for disaster stricken regions by terrestrial and aerial transportation networks is provided, simultaneously, which in turn increases route reliability and reduces travel time. In other words, in an earthquake, a lot of infrastructures are damaged and the damage can increase in aftershocks; also, some of the disaster areas may not have good condition for helicopters to land and put the lives of relief personnel at risk. In this study, to avoid more casualties, we offer the route reliability of each vehicle as the possibility of successfully delivering relief to all the demand points on the route of each vehicle.

In the proposed problem, transferring aids from
DCs to the disaster stricken regions is done in the way. That is, first, a subset of DCs are determined to be opened. Then, the suppliers begin their tasks in the established DCs. Crisis areas and vehicles will also be assigned to DCs. As soon as the volume of demand needed for each crisis area is larger than the capacity of the vehicle, split delivery is required and any disaster stricken region can receive service more than once by distinct vehicles. Heterogeneous vehicles with different speeds and capacities are taken into account and the vehicles in the last node that do not return to where they started moving wait until the next mission is specified. Thus, each disaster area can be considered as a new distribution center.

\subsection{Assumptions}

- All transportations are considered to be multi-mode (ground and air). In addition to the crisis areas that are available by ground vehicles, those that need helicopters due to the damage to the routes and roads as well as long distance are considered;

- Fleet is not homogenous and the vehicles are dissimilar in terms of speed and capacity;

- The numbers of disaster stricken regions and DCs are known. The distance between the regions is available. The route reliability can be detected with advanced technology and communication skills in real time;

- Any vehicle is permitted to transfer different kinds of relief in each assignment. This means that any vehicles is permitted to be loaded by different types of relief at the same time;

- The awareness of information (demand, cost, etc.) is not complete. In actual humanitarian operations, it is often seen that in the first phase of disaster, re- 
sponse is uncertain. Also, the complex and dynamic nature of various actors in a relief chain suggests the importance of uncertainty in the decision-making on relief chain. Accordingly, in this model, the cost and amount of relief available are considered as uncertain parameters.

\subsection{Notations and definitions}

\section{Sets and indices}

$N \quad$ Set of disaster stricken regions

$$
\{1, \cdots \cdots, n\}
$$

$M \quad$ Set of candidate DCs

$$
\{n+1, \cdots \cdots, n+m\}
$$

$V \quad$ Set of nodes $\{1, \cdots \cdots, n+m\}$

$H \quad$ Set of aerial vehicles $\{1, \cdots \cdots, h\}$

$G \quad$ Set of terrestrial vehicles $\{1, \cdots \cdots, g\}$

$L \quad$ Set of aids $\{1, \cdots \cdots, l\}$

$E \quad$ Set of accessible traffic links $\{(i, j), i, j \in v, i \neq j\}$

$i, j \quad$ Indices to nodes $i, j \in v$

$l \quad$ Indices to aid

$h \quad$ Indices to aerial vehicles

$g \quad$ Indices to terrestrial vehicles

\section{Parameters}

$f_{j} \quad$ Fixed cost of establishing the $\mathrm{DC} j$, $\forall j \in M$

$d_{i j} \quad$ Distance of link $(i, j), \forall(i, j) \in E$

$r_{i j} \quad$ Probability of crossing arc $(i, j)$ successfully, $\forall(i, j) \in E$

$D_{i l} \quad$ Quantity of aid 1 demanded by crisis area $i$

$u \nu_{l} \quad$ Unit volume of relief $l, \forall l \in L$

$Q_{l} \quad$ Amount of aid 1 available in traffic network, $\forall l \in L$

$c_{g} \quad$ Transportation cost per kilometer of terrestrial vehicle $g, \forall g \in G$

$c_{h} \quad$ Transportation cost per kilometer of aerial vehicle $h, \forall h \in H$

$\nu_{g} \quad$ Normal speed of terrestrial vehicle $g$, $\forall g \in G$

$\nu_{h} \quad$ Normal speed of aerial vehicle $h$, $\forall h \in H$

$l_{h} \quad$ Loading capacity of aerial vehicle $h$, $\forall h \in H$

$l_{g} \quad$ Loading capacity of terrestrial vehicle $g, \forall g \in G$

Decision variables

$x_{j} \quad 1$ if candidate DC $j$ is opened, 0 else, $\forall i \in j$

$y_{i j h} \quad 1$ if $i$ precedes $j$ in the route of aerial vehicle $h, 0$ else; $y_{i j g} \quad 1$ if $i$ precedes $j$ in the route of terrestrial vehicle $h, 0$ else, $\forall g \in G,(i, j) \in E$

$z_{i h} \quad 1$ if $i$ is on the route of aerial vehicle $h$, 0 else, $\forall h \in H,(i, j) \in E$

$z_{i g} \quad 1$ if $i$ is on the route of terrestrial vehicle $h, 0$ else, $\forall g \in G,(i, g) \in E$

$V F_{i h} \quad 1$ if the last demand area serviced by aerial vehicle $h$ is node, $i \in N, 0$ else

$V F_{i g} \quad 1$ if the last demand area serviced by terrestrial vehicle $g$ is node $i \in N, 0$ else

de $\nu_{i l} \quad$ Amount of unsatisfied demand aid type $l$ at node $i$ at the end of the operation

$q_{\text {ilh }} \quad$ Quantity of aid $l$ distributed by $h$ to demand area $i, \forall h \in H, \forall l \in L, \forall i \in N$

$q_{i l g} \quad$ Quantity of aid $l$ distributed by $g$ to demand area $i, \forall g \in G, \forall l \in L, \forall i \in N$

\subsection{Model}

3.3.1. Objective functions

Objective (1). Minimizing relief distribution costs: OLRP simultaneously determines the number and location of DCs as well as assigns earthquake stricken areas to DCs and vehicle routes such that the total cost includes two parts: (1) the fixed cost to establish DCs $(j \in M)$, and (2) the travel cost of air and ground vehicles. We can write the objective function (1) as follows:

$$
\begin{aligned}
\min Z_{1}= & \sum_{j \in M} f_{j} x_{j}+\sum_{h \in H} \sum_{(i, j) \in E} c_{h} d_{i j} y_{i j h} \\
& +\sum_{g \in G} \sum_{(i, j) \in E} c_{g} d_{i j} y_{i j g} .
\end{aligned}
$$

Objective (2). Minimizing the maximum traveling time of vehicle route: Times $t_{i j g}$ and $t_{i j h}$ as well as the normal speeds $V_{h}$ and $V_{g}$ are respectively related to vehicles $h$ and $g$, which cross the arc $(i, j) \in E$ with $d_{(i, j)}$. If we do not consider service time (pickup and delivery times), we can assume that the departure time for serving vehicles from DCs is zero and the traveling time for aerial mode of transportation $\left(t_{h}\right)$ is equal to the total traveling time needed to pass through all the connectors on the vehicle route $h$.

$$
t_{h}=\sum_{(i, j) \in E} t_{i j h}=\sum_{(i, j) \in E} \frac{d_{i j} y_{i j h}}{\left(v_{h}\right)} .
$$

Also, travel time for ground vehicle $\left(t_{g}\right)$ is equivalent to the total travel time through all connectors on the route of vehicle $g$.

$$
t_{g}=\sum_{(i, j) \in E} t_{i j g}=\sum_{(i, j) \in E} \frac{d_{i j} y_{i j g}}{\left(v_{g}\right)} .
$$


Objective 2 can be formulated as follows:

$$
\begin{aligned}
\min Z_{2}= & \max \left\{\sum_{(i, j) \in E} \frac{d_{i j} y_{i j h}}{v_{h}},\right. \\
& \left.\sum_{(i, j) \in E} \frac{d_{i j} y_{i j g}}{v_{g}} \quad h \in H, g \in G\right\} .
\end{aligned}
$$

Objective (3). Maximizing the minimum route reliability: Earthquake can seriously damage different infrastructures (bridges, tunnels, etc.) and there is a great probability for more damages in aftershocks; also, some of the disaster stricken regions may not have good condition for helicopters to land and put the lives of relief personnel at risk. In this study, to avoid more casualties, we conceptualize the route reliability of each vehicle as the probability of rescuing the workers to deliver aid to all demand areas on the vehicle route. $P_{g}$ and $P_{h}$ indicates the reliability of vehicles $g$ and $h$ to complete their relevant distribution activities, successfully, assuming that the connections on each vehicle are independent of each other.

$$
P_{g}=r_{01} \times r_{12} \times \cdots \cdots \times r_{(n-1) n}=\prod_{(i, j) \in E_{g}} r_{i j}
$$

and

$$
P_{h}=r_{01} \times r_{12} \times \cdots \cdots \times r_{(n-1) n}=\prod_{(i, j) \in E_{h}} r_{i, j}
$$

Objective 3, which shows the reliability of the entire distribution process in emergency chain, is formulated as follows:

$$
\begin{gathered}
\max Z_{3}=\min \left\{\prod_{\substack{(i, j) \in E, y_{i j h}=1}} r_{i j h}, \prod_{\substack{(i, j) \in E, y_{i j g}=1}} r_{i j g}\right. \\
\forall h \in H, \forall g \in G\} .
\end{gathered}
$$

\subsubsection{Contains of the moded}

$$
\begin{aligned}
& \text { s.t. } \\
& x_{i} \geq y_{i j h}, \quad \forall i \in M, \quad(i, j) \in E, \quad h \in H: i \neq j, \\
& x_{i} \geq y_{i j g}, \quad \forall i \in M, \quad(i, j) \in E, \quad g \in G: i \neq j, \\
& x_{i} \geq z_{i h}, \quad \forall i \in M, \quad(i, j) \in E, \quad h \in H, \\
& x_{i} \geq z_{i g}, \quad \forall i \in M, \quad(i, j) \in E, \quad g \in G, \\
& z_{i h} \geq y_{i j h}, \quad \forall i \in V, \quad(i, j) \in E, h \in H: i \neq j,
\end{aligned}
$$

$$
\begin{aligned}
& z_{i g} \geq y_{i j g}, \quad \forall i \in V, \quad(i, j) \in E, g \in G: i \neq j, \\
& z_{i h} \geq V F_{i h}, \quad \forall i \in V, \quad h \in H, \\
& z_{i g} \geq V F_{i g}, \quad \forall i \in V, \quad g \in G, \\
& \sum_{i \in V} V F_{i h}=1, \quad \forall h \in H, \\
& \sum_{i \in V} V F_{i g}=1, \quad \forall g \in G, \\
& \sum_{h \in H} y_{i j h}+\sum_{g \in G} y_{i j g} \leq 1, \quad \forall(i, j) \in E: i \neq j, \\
& \sum_{h \in H} y_{i j h} \leq 1, \quad \forall(i, j) \in E: i \neq j, \\
& \sum_{g \in G} y_{i j g} \leq 1, \quad \forall(i, j) \in E: i \neq j \\
& \sum_{j \in V} y_{j i h} \leq 1, \quad \forall i \in N, h \in H: i \neq j \\
& \sum_{j \in V} y_{j i g} \leq 1, \quad \forall i \in N, g \in G: i \neq j \\
&
\end{aligned}
$$

$\sum_{i \in M} \sum_{j \in N} y_{i j h} \leq 1, \quad \forall h \in H$,

$\sum_{i \in M} \sum_{j \in N} y_{i j g} \leq 1, \quad \forall g \in G$

$\sum_{i \in M} \sum_{j \in N} \sum_{h \in H} q_{j l h} z_{i h}+\sum_{i \in M} \sum_{j \in N} \sum_{g \in G} q_{j l g} z_{i g} \leq Q_{l}$

$\forall l \in L$,

$\operatorname{deV}_{j l}=D_{j l}-\left(\sum_{h \in H} q_{j l h}+\sum_{g \in G} q_{j l g}\right) \geq O$

$$
\forall j \in N, l \in L
$$

$\sum_{j \in N} \sum_{l \in L} u v_{l} q_{j l h} \leq L_{h}, \quad \forall h \in H$

$$
\sum_{j \in N} \sum_{l \in L} u v_{l} q_{j l g} \leq L_{g}, \quad \forall g \in G
$$

$$
\begin{aligned}
& \sum_{j /(j, i) \in E} y_{j i h}-\sum_{j /(i, j) \in E} y_{i j h} \\
& = \begin{cases}1 & V F_{i h}=1, \quad i \in N: i \neq j \\
-1 & z_{i h}=1, \quad i \in M, \quad \forall h \in H: i \neq j \\
0 & \text { else }\end{cases}
\end{aligned}
$$




$$
\begin{aligned}
& \sum_{j /(j, i) \in E} y_{j i g}-\sum_{j /(j, i) \in E} y_{i j g} \\
& = \begin{cases}1 & V F_{i g}=1, \quad i \in N: i \neq j \\
-1 & z_{i g}=1, \quad i \in M, \forall g \in G: i \neq j, \\
0 & \text { else }\end{cases}
\end{aligned}
$$

$\sum_{i \in V} \sum_{h \in H} y_{i j h}+\sum_{i \in V} \sum_{g \in G} y_{i j g} \geq 1, \quad \forall j \in N$,

$$
\sum_{i \in M} y_{i j h}=O, \quad \forall j \in M, h \in H
$$

$$
\sum_{i \in M} y_{i j g}=O, \quad \forall j \in M, g \in G
$$

$$
u_{i h}-u_{j h}+n * y_{i j h} \leq n-1,
$$

$$
\forall i, j \in N, h \in H: i \neq j
$$$$
u_{i g}-u_{j g}+n * y_{i j g} \leq n-1,
$$$$
\forall i, j \in N, g \in G: i \neq j
$$

$$
q_{i l h} \geq O, \quad \forall(i, j) \in E, l \in L, h \in H,
$$

$q_{i l g} \geq O, \quad \forall(i, j) \in E, l \in L, g \in G$,

$x_{i} \in(0,1), \quad \forall i \in M$,

$$
y_{i j h}, y_{i j g} \in(0,1), \quad \forall(i, j) \in E, h \in H, g \in G,
$$

$$
\begin{aligned}
& Z_{i h}, Z_{i g} \in(0,1), \quad \forall i \in V, h \in H, g \in G, \\
& V F_{i h}, V F_{i g} \in(0,1), \quad \forall i \in N, h \in H, g \in G, \\
& u_{i h}, u_{i g} \in(., 1), \quad \forall i \in N, h \in H, g \in G .
\end{aligned}
$$

Constraints (8)-(11) ensure that only established distribution centers can provide service. Constraints (12) and (13) guarantee that any vehicle (aerial or terrestrial) can travel via arc $(i, j)$ if and only if node $i$ is in the path of any vehicle (aerial or terrestrial). Constraints (14) and (15) indicate that the node located at the end of the route of any vehicle should be served by the same vehicle. Eqs. (16) and (17) show that any vehicle (aerial or terrestrial) must finally remain only in one node. Constraints (18)-(20) ensure that only one of the aerial or terrestrial ambulances is selected for each path. Constraints (21) and (22) ensure that any vehicle (aerial or terrestrial) serves at most once in any disaster area. Constraints (23) and (24) ensure that any vehicle (aerial or terrestrial) is dispatched from at most one DC. Constraint (25) ensures that the amount of aid distributed to disaster areas from all DCs does not exceed the available amount of relief. Constraint (26) indicates that the relief $l$ allocated to each node is less than or equal to the demand of the node. Constraints (27) and (28) ensure that the amount of all the aid distributed to earthquake stricken areas by vehicles (aerial or terrestrial) does not exceed their capacity. Eqs. (29) and (30) express the consecutive movement, and ensure the assumption of openness of path. Eq. (31) shows that each disaster stricken zone can be visited at minimum once; the assumption of split delivery in this constraint has been well illustrated. Constraints (32) and (33) ensure that distribution centers are not related to each other. Eqs. (34) and (35) are constraints of sub-tour elimination. Constraints (36)-(42) are the limitations on the decision variables.

The presented model has been given in this section, assuming that parameters are certain. In the real world, there is uncertainty in many of these parameters. To get closer to the real conditions, in the next section, the model will be developed in uncertain conditions. To develop the model, robust optimization approach is used.

\subsection{Linearization of the model}

In dealing with the real-world decision problems, we face problems in which each of the objective functions or constraints can be considered as a non-linear function. In the model presented in Section 3.3, Objectives 2 and 3 as well as constraint (25) were nonlinear. In this section, the linearization of the equation is addressed. Non-linear Eq. (4), which has been defined for the objective function of time in Section 3.3, becomes linear as follows:

$\min t$

$$
\begin{array}{ll}
t \geq \sum_{(i, j) \in E} \frac{d_{i j} y_{i j h}}{v_{h}}, & \forall h \in H, \\
t \geq \sum_{(i, j) \in E} \frac{d_{i j} y_{i j g}}{v_{g}}, & \forall g \in G .
\end{array}
$$

Also, non-linear Eq. (7) becomes linear for the objective function of the reliability as follows:

$\max p$,

$$
\begin{aligned}
& p \leq \prod_{\substack{(i, j) \in E, y_{i j h}=1}} r_{i j h} \quad \forall h \in H, \\
& p \leq \prod_{\substack{(i, j) \in E, y_{i j g}=1}} r_{i j g} \quad \forall g \in G .
\end{aligned}
$$

In this equation, the probabilities of $r_{i j h}$ and $r_{i j g}$ are between 0 and 1 , the variables $y_{i j h}$ and $y_{i j g}$ 
are binary variables if one of them becomes zero, and the objective function value will be zero. Thus, the reliability of the routes must be calculated for the vehicles to pass through them; therefore, rather than maximizing $\mathrm{p}$, we can maximize $p^{\prime}=a+f(x)$ that can be defined as follows:

$$
\begin{aligned}
& \max p^{\prime}, \\
& p^{\prime} \leq\left\{\prod_{(i, j) \in E}\left(r_{i j h} y_{i j h}+1-y_{i j h}\right)\right\} \quad \forall h \in H, \\
& p^{\prime} \leq\left\{\prod_{(i, j) \in E}\left(r_{i j g} y_{i j g}+1-y_{i j g}\right)\right\} \quad \forall g \in G .
\end{aligned}
$$

With this change, if one of the variables of $y$ is 0 , the target function will not be 0 .

$$
\begin{aligned}
& \left(r_{i j h} y_{i j h}+1-y_{i j h}\right)= \begin{cases}1, & y_{i j h}=0 \\
r_{i j h}, & y_{i j h}=1\end{cases} \\
& \left(r_{i j g} y_{i j g}+1-y_{i j g}\right)= \begin{cases}1, & y_{i j g}=0 \\
r_{i j g}, & y_{i j g}=1\end{cases}
\end{aligned}
$$

Now, the nonlinear constraint (25) is converted to linear constraint as follows:

First, we define two positive variables: $q z_{i j l h}$ and $q z_{i j l g}$ :

$$
\begin{aligned}
& q z_{i j l h} \geq q_{j l h}-\left(1-z_{i h}\right) * \text { bigm } \\
& q z_{i j l h} \leq z_{i h} * \text { bigm, } \\
& q z_{i j l h} \leq q_{j l h} \\
& q z_{i j l g} \geq q_{j l g}-\left(1-z_{i g}\right) * \text { bigm } \\
& q z_{i j l g} \leq z_{i g} * \text { bigm, } \\
& q z_{i j l g} \leq q_{j l g} .
\end{aligned}
$$$$
\sum_{i \in M} \sum_{j \in N} \sum_{h \in H} q z_{i j l h}+\sum_{i \in M} \sum_{j \in N} \sum_{g \in G} q z_{i j l g} \leq Q_{l}
$$

\subsection{Robust counterpart mathematical model-box uncertainty}

In order to develop the robust counterpart of the proposed model, the fixed cost of opening distribution centers, transportation costs between the points, and the amount of the first aid available in the network are the uncertain parameters. In robust optimization approach, linear programming model changes to its robust counterpart model. In our model, we change each uncertain factor in a closed bounded box [29,31]. The overview of the box is as follows:

$$
u_{\mathrm{Box}}=\left\{\xi \in \Re^{n}:\left|\xi_{t}-\overline{\xi_{t}}\right| \leq \rho G_{t}, \quad t=1,2, \cdots, n\right\},
$$

where $\bar{\xi}_{t}$ is the $\xi_{t}$ th normal value or the $t$ th parameter of vector $\xi$ the positive value of $G_{t}$ represents a "scale of uncertainty" and $\rho>0$ is "level of uncertainty." A particular case with $G_{t}=\bar{\xi}_{t}$ is related to the state in which relative deviation $\xi_{t}$ of nominal data is as large as $\rho$. We suggest the following sources [29,32] for further information on robust optimization approach. It should be noted that in order to simplify the robust optimization approach in the objective function, first, $c_{h} d_{i j}$ and then, $\mathcal{A}_{i j h}, c_{g} d_{i j}$, and $\mathcal{B}_{i j g}$ are considered. Therefore, we have:

$\min Z_{1}$

$$
\begin{aligned}
& \min Z_{2}= \max \left\{\sum_{(i, j) \in E} \frac{d_{i j} y_{i j h}}{v_{h}}\right. \\
&\left.\sum_{(i, j) \in E} \frac{d_{i j} y_{i j g}}{v_{g}} h \in H, g \in G\right\}, \\
& \max Z_{3}= \min \left\{\prod_{\substack{(i, j) \in E, y_{i j h}=1}} r_{i j h}, \prod_{\substack{(i, j) \in E, y_{i j g}=1}} r_{i j g}\right. \\
&\forall h \in H, \forall g \in G\},
\end{aligned}
$$

s.t.

$$
\begin{aligned}
& \sum_{j \in M}\left(\bar{f}_{J} x_{j}+\eta_{j}^{f}\right) \\
& +\sum_{h \in H} \sum_{(i, j) \in E}\left(\overline{\mathcal{A}_{i J h}} y_{i j h}+\eta_{i j h}^{\mathcal{A}}\right) \\
& \quad+\sum_{g \in G} \sum_{(i, j) \in E}\left(\overline{\mathcal{B}_{l J g}} y_{i J g}+\eta_{i j g}^{\mathcal{B}}\right) \leq Z_{1},
\end{aligned}
$$

$\rho_{f} \mathcal{G}_{j}^{f} \leq \eta_{j}^{f} \quad \forall j$,

$\rho_{f} \mathcal{G}_{j}^{f} \geq-\eta_{j}^{f} \quad \forall j$,

$\rho_{\mathcal{A}} \mathcal{G}_{i j h}^{\mathcal{A}} \leq \eta_{i j h}^{\mathcal{A}} \quad \forall i, j, h$,

$\rho_{\mathcal{A}} \mathcal{G}_{i j h}^{\mathcal{A}} \geq-\eta_{i j h}^{\mathcal{A}} \quad \forall i, j, h$,

$\rho_{\mathcal{B}} \mathcal{G}_{i j g}^{\mathcal{B}} \leq \eta_{i j g}^{\mathcal{B}} \quad \forall i, j, g$,

$\rho_{\mathcal{B}} \mathcal{G}_{i j g}^{\mathcal{B}} \geq-\eta_{i j g}^{\mathcal{B}} \quad \forall i, j, g$,

$x_{i} \geq y_{i j h}, \quad \forall i \in M,(i, j) \in E, h \in H: i \neq j$, 


$$
\begin{aligned}
& x_{i} \geq y_{i j g}, \quad \forall i \in M,(i, j) \in E, g \in G: i \neq j, \\
& x_{i} \geq z_{i h}, \quad \forall i \in M,(i, j) \in E, h \in H, \\
& x_{i} \geq z_{i g}, \quad \forall i \in M,(i, j) \in E, g \in G, \\
& z_{i h} \geq y_{i j h}, \quad \forall i \in V,(i, j) \in E, h \in H: i \neq j, \\
& z_{i g} \geq y_{i j g}, \quad \forall i \in V,(i, j) \in E, g \in G: i \neq j \\
& z_{i h} \geq V F_{i h}, \quad \forall i \in V, h \in H, \\
& z_{i g} \geq V F_{i g}, \quad \forall i \in V, g \in G, \\
& \sum_{i \in V} V F_{i h}=1, \quad \forall h \in H, \\
& \sum_{i \in V} V F_{i g}=1, \quad \forall g \in G \\
& \sum_{h \in H} y_{i j h}+\sum_{g \in G} y_{i j g} \leq 1, \quad \forall(i, j) \in E: i \neq j, \\
& \sum_{h \in H} y_{i j h} \leq 1, \quad \forall(i, j) \in E: i \neq j, \\
& \sum_{g \in G} y_{i j g} \leq 1, \quad \forall(i, j) \in E: i \neq j \\
& \sum_{j \in V} y_{j i h} \leq 1, \quad \forall i \in N, h \in H: i \neq j, \\
& \sum_{j \in V} y_{j i g} \leq 1, \quad \forall i \in N, g \in G: i \neq j, \\
& \sum_{i \in M} \sum_{j \in N} y_{i j h} \leq 1, \quad \forall h \in H, \\
& \sum_{i \in M} \sum_{j \in N} y_{i j g} \leq 1, \quad \forall g \in G, \\
& \sum_{i \in M} \sum_{j \in N} \sum_{h \in H} q_{j l h} z_{i h}
\end{aligned}
$$$$
+\sum_{i \in M} \sum_{j \in N} \sum_{g \in G} q_{j l g} z_{i g} \leq \overline{Q_{l}}-\rho_{Q} \mathcal{G}_{l}^{Q}
$$$$
d e V_{j l}=D_{j l}-\left(\sum_{h \in H} q_{j l h}+\sum_{g \in G} q_{j l g}\right) \geq O
$$$$
\forall j \in N, l \in L
$$$$
\sum_{j \in N} \sum_{l \in L} u v_{l} q_{j l h} \leq L_{h}, \quad \forall h \in H
$$$$
\sum_{j \in N} \sum_{l \in L} u v_{l} q_{j l g} \leq L_{g}, \quad \forall g \in G,
$$

$$
\begin{aligned}
& \sum_{j /(j, i) \in E} y_{j i h}-\sum_{j /(i, j) \in E} y_{i j h} \\
& \quad= \begin{cases}1 & V F_{i h}=1, \quad i \in N: i \neq j \\
-1 & z_{i h}=1 \quad i \in M, \forall h \in H: i \neq j \\
0 & \text { else }\end{cases}
\end{aligned}
$$$$
\sum_{j /(j, i) \in E} y_{j i g}-\sum_{j /(j, i) \in E} y_{i j g}
$$$$
=\left\{\begin{array}{ll}
1 & V F_{i g}=1, \quad i \in N: i \neq j \\
-1 & z_{i g}=1 \\
0 & \text { else }
\end{array} \quad i \in M, \forall g \in G: i \neq j,\right.
$$$$
\sum_{i \in V} \sum_{h \in H} y_{i j h}+\sum_{i \in V} \sum_{g \in G} y_{i j g} \geq 1, \quad \forall j \in N
$$$$
\sum_{i \in M} y_{i j h}=O, \quad \forall j \in M, h \in H,
$$$$
\sum_{i \in M} y_{i j g}=O, \quad \forall j \in M, g \in G,
$$

$$
\begin{array}{r}
u_{i h}-u_{j h}+n * y_{i j h} \leq n-1, \\
\forall i, j \in N, h \in H: i \neq j, \\
u_{i g}-u_{j g}+n * y_{i j g} \leq n-1, \\
\forall i, j \in N, g \in G: i \neq j,
\end{array}
$$

$q_{i l h} \geq O, \quad \forall(i, j) \in E, l \in L, h \in H$,

$$
q_{i l g} \geq O, \quad \forall(i, j) \in E, l \in L, g \in G,
$$

$x_{i} \in(0,1), \quad \forall i \in M$,

$y_{i j h}, y_{i j g} \in(0,1), \quad \forall(i, j) \in E, h \in H, g \in G$,

$$
Z_{i h}, Z_{i g} \in(0,1), \quad \forall i \in V, h \in H, g \in G
$$

$V F_{i h}, V F_{i g} \in(0,1), \quad \forall i \in N, h \in H, g \in G$,

$u_{i h}, u_{i g} \in(0,1), \quad \forall i \in N, h \in H, g \in G$.

\section{Solution approach}

In order to solve multi-objective mathematical programming models (MOLP), different methods have been proposed in previous studies. Among these methods, fuzzy programming approaches have wide application. The first fuzzy solution to MOLP problems developed by Zimmermann [33] was min-max 
method; however, the solutions offered by this method were highly inefficient and ineffective [34]. Therefore, several methods were proposed to overcome this defect. Mahaptra and Roy [35], to solve their multi-objective problem, improved the max-min method. In this improved approach, the decision maker could achieve the optimal results based on their expectations. Also, Islam and Roy [36] presented a new fuzzy multiobjective planning method called PGP. To resolve the weakness of min-max approach, Lai and Hwang [34] provided an interactive fuzzy approach, called LH method, to solve MOLP problems. Also, Selim and Ozkarah [37] presented a new fuzzy method called MW for solving multi-objective problems. In this method, they took advantage of a modified merged function based on Werner [38] method. Li et al. [39] proposed a two-stage fuzzy model called LZL. Finally, Torabi and Hassini [30] utilized these models for solving their multi-objective problem in a series of elementary numerical experiments and found some defects. Single-step models such as LH and MW solve the main model straightforwardly by an adjunctive certain model. Sometimes, LH model provides ineffective solutions dominated by the solution to LZL model. MW model usually gives a useful solution, which is poorly compromised. Thus, satisfaction degree of objectives may have significant differences, which is not acceptable for the decision-maker. However, LZL always produces an efficacious solution, but a twostage one that requires more calculations than singlestage models. Therefore, Torabi and Hassini [30] proposed a new single-stage fuzzy solution, called TH, for solving multi-objective problems, which eliminated the disadvantages of previous methods. Their $\mathrm{TH}$ method was in fact a combination of $\mathrm{LH}$ and $\mathrm{MW}$ methods. A solution method by combining the method provided in the antecedent section with a fuzzy solution approach derived from Torabi and Hassini [30] is used in this research to solve the offered model.

Steps of the offered hybrid solutions approach are summarized as follows:

Step 1. Determining the parameters and variables of uncertainty and considering the distribution functions required in the model;

Step 2. Formulating the proposed model with the parameters defined in the previous step;

Step 3. Converting the constraints of mixed-integer programming model to constraints of the certain counterpart by applying the approach outlined in the antecedent section;

Step 4. Converting the robust model to the equivalent certainty model by applying the approach outlined in the previous section;

Step 5. Determining the positive ideal and negative ideal solutions to $\alpha$ for every objective function in which $\alpha$ is the possible level. To calculate the positive and negative ideal solutions, i.e., $\mathcal{W}_{1}^{P I S}, x_{1}^{P I S}$ and $\mathcal{W}_{2}^{P I S}, x_{2}^{P I S}$ each certainty model is separately solved for each of the objective functions and the positive ideal solution is obtained; then, the negative ideal solution is estimated as follows:

$$
\mathcal{W}_{1}^{N I S}=\mathcal{W}_{1}\left(x_{2}^{P I S}\right), \quad \mathcal{W}_{2}^{N I S}=\mathcal{W}_{2}\left(x_{1}^{P I S}\right) .
$$

Step 6. Calculating a linear membership function using the formulation below. It is done for each objective function.

$$
\begin{aligned}
& \mu_{1}(x)=\left\{\begin{array}{l}
1 \\
\frac{\mathcal{W}_{1}^{N I S}-\mathcal{W}_{1}}{\mathcal{W}_{1}^{N I S}-\mathcal{W}_{1}^{P I S}} \\
0
\end{array}\right. \\
& \text { if } \mathcal{W}_{1}<\mathcal{W}_{1}^{P I S} \\
& \text { if } \mathcal{W}_{1}^{P I S} \leq \mathcal{W}_{1} \leq \mathcal{W}_{1}^{N I S} \\
& \text { if } \mathcal{W}_{1}>\mathcal{W}_{1}^{N I S} \\
& \mu_{2}(x)=\left\{\begin{array}{l}
1 \\
\frac{\mathcal{W}_{2}-\mathcal{W}_{2}^{N I S}}{\mathcal{W}_{2}^{P I S}-\mathcal{W}_{2}^{N I S}} \\
0
\end{array}\right. \\
& \text { if } \mathcal{W}_{2}<\mathcal{W}_{2}^{\text {PIS }} \\
& \text { if } \mathcal{W}_{2}^{N I S} \leq \mathcal{W}_{2} \leq \mathcal{W}_{2}^{P I S} \\
& \text { if } \mathcal{W}_{2}>\mathcal{W}_{2}^{N I S}
\end{aligned}
$$

In fact, $\mu_{h}(x)$ represents the satisfaction degree of the $h$ th objective function. It should be noted that $\mu_{1}(x)$ has been used for minimizing objective functions and $\mu_{2}(x)$ for maximizing objective functions;

Step 7. Converting the certainty mixed integer programming model to a certainty single-objective mixed integer programming model using the integrated function, which is calculated as follows:

$$
\max \lambda(x)=\psi \lambda_{0}+(1-\psi) \sum_{h} \theta_{h} \mu_{h}(x)
$$

s.t.

$$
\begin{aligned}
& \lambda_{0} \leq \mu_{h}(x), \quad h=1,2 \\
& x \in F(x), \quad \lambda_{0} \text { and } \lambda \in[0,1],
\end{aligned}
$$

in which $\mu_{h}(x)$ and $\lambda_{0}=\min \left\{\mu_{h}(x)\right\}$, respectively, show the satisfaction degree of the $h$ th objective function and minimum degree of objectives satisfaction. This formulation is determined as a convex combination of the lower bound of satisfaction degree of functions $\lambda_{0}$ and total weight of these degrees to achieve $\mu_{h}(x)$, which guarantees obtaining a balanced solution. In addition, $\theta_{h}$ and $\psi$, respectively, indicate relative importance of the $h$ th objective function and coefficient of restitution. Parameter $\theta_{h}$ is specified by the decision-maker based on $\Sigma_{h} \theta_{h}=1$ and $\theta_{h}>0$. Also, the parameter $\psi$ controls the minimum level of objectives satisfaction and the importance degrees of the objectives. TH method is capable to obtain balanced and unbalanced solutions based on preferences 
of the decision-maker through setting the parameter $\psi$. High value of the parameter $\psi$ means that a high low bound has been considered for satisfaction degree of objectives $\left(\lambda_{0}\right)$ and more objective solutions will be achieved. In contrast, low value of $\psi$ means that obtaining an optimal solution, showing a high level of satisfaction for the same relative important objectives regardless of satisfaction degree of other objectives, has been considered [30];

Step 8. Determining the parameters $\theta_{h}, \rho$, and $\psi$ and solving single-objective models created in the previous step. If the answer is satisfactory for decision makers, stop the process; otherwise, in order to achieve new answers, change the values of parameters $\psi$ and $\rho$ and if needed, change the value of $\theta_{h}$.

\section{Computational results}

In this section, in order to evaluate the validity of the offered model and show the efficiency of the offered solution methodology, first, a case study of relief distribution in the post-earthquake time is presented and then, to further investigate the performance of the model, a series of additional tests are randomly generated.

\subsection{The case study}

The earthquake of the southern region of Arasbaran in East Azarbaijan province in Iran (towns of Ahar, Varzaghan, and Harris) with a magnitude of 6.2 on the Richter scale caused the death of about 320 people, destroyed more than 160 villages, and damaged 250 villages. Ahar-Varzeghan earthquake in the present century, along with the 1930 Salmas earthquake and 1996 Golestan Ardebil earthquake, is among the most devastating earthquakes in northwestern provinces of Iran. The earthquake was felt in most northern provinces of Iran and neighboring countries (Azerbaijan, Armenia, and Turkey) in a radius of over $300 \mathrm{~km}$. The events of landslide and rock fall, as the area was mountainous; communication cut-off; roads breakdown; and damage to bridges caused additional problems for the rescue groups; also, the events of the main earthquake and its aftershocks disturbed the traffic of the rescue teams.

In this study, three cities (Kharvana, Tabriz, and Duzduzan) where the intensity of earthquake was lower and without serious injury were considered as candidates to establish distribution centers. Also, 11 areas among Ahar, Haris, and Varzeghan where the damage was so severe were targeted for relief. The relief items that were needed in the early hours after the event, including water and tents for temporary housing of people, were considered for distribution. Also, one helicopter and two trucks were considered to transport goods to these areas. Relief from other provinces and towns of the country were collected, which were not within the scope of this research.

Information on candidate distribution centers is shown in Table A.1. The parameters of the relief are given in Table A.2, in which the sizes of tents and boxes of mineral water have been used as a benchmark for measuring the equivalent volume. The capacity and speed of each vehicle are shown in Table A.3. Relief needs and demand for each earthquake stricken area on the first day after the earthquake are shown in Table A.4. It should be noted that for the information on the deployment of vehicles for transport, network traffic should be determined, which can be obtained through aerial photos taken instantly after the earthquake. In addition, based on the human resources and related equipment, the plan, length, the reliability of the roads would be known and estimable (see Tables A.1 to A.4 in Appendix A).

In this study, two uncertainty and certainty conditions have been solved using the approach proposed in Section 4 by GAMS Software. In this solution, the importance of the objective functions has been considered as $\theta=0.3,0.3$, and 0.4 respectively. Also, the penalty factor is taken into account as $\varphi=0.4$. To solve the problem in uncertainty condition, uncertainty has been considered at three levels $\rho=0.3,0.5,0.7$. Figure 2 shows the solution under certainty. As it is observed, distribution center no. 13 is opened and vehicles appropriate to the route and the demand of the disaster area have been allocated. It can be seen that in order to give service to the demand point no. 6, helicopter has been used that could decrease not only the frequency of distribution but also the travel time. It could also increase the route reliability. The resulting total cost is 8583.5 and the longest travel time is 16 hours, and the reliability achieved is 0.81 . Figure 3 shows the solution under uncertainty condition, in which the distribution center no. 14 has been opened and the routes for the vehicles have been recovered. In uncertainty condition, the value obtained for the total cost is 11710.79 , the latest travel time is 18.08 , and the reliability is 0.805 . The solution time under certainty is 14 minutes and 37 seconds, whereas in uncertainty, the solution time increases to 16 minutes and 40 seconds. In the following, in Table 2, the percentage of the estimated demand in disaster locations has been determined under uncertainty and certainty conditions.

\subsection{Generating testing problems}

To demonstrate the credibility of the proposed model and the efficiency of the proposed solution, in addition to the case study offered in the antecedent section, several tests were run of which the numerical results are reported in this section. To this end, five problems with different aspects were considered; the results are 


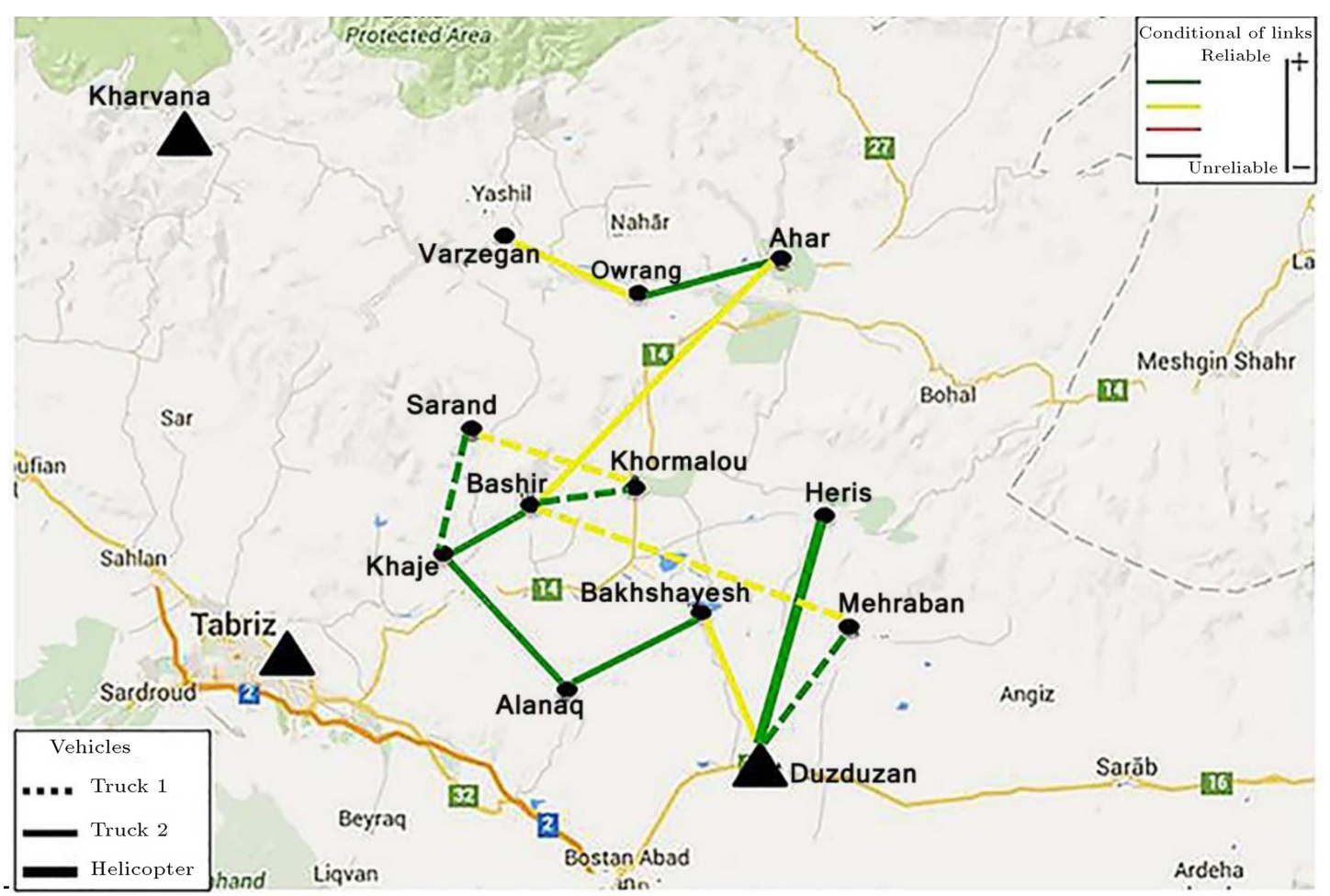

Figure 2. Transportation network in certainty condition.

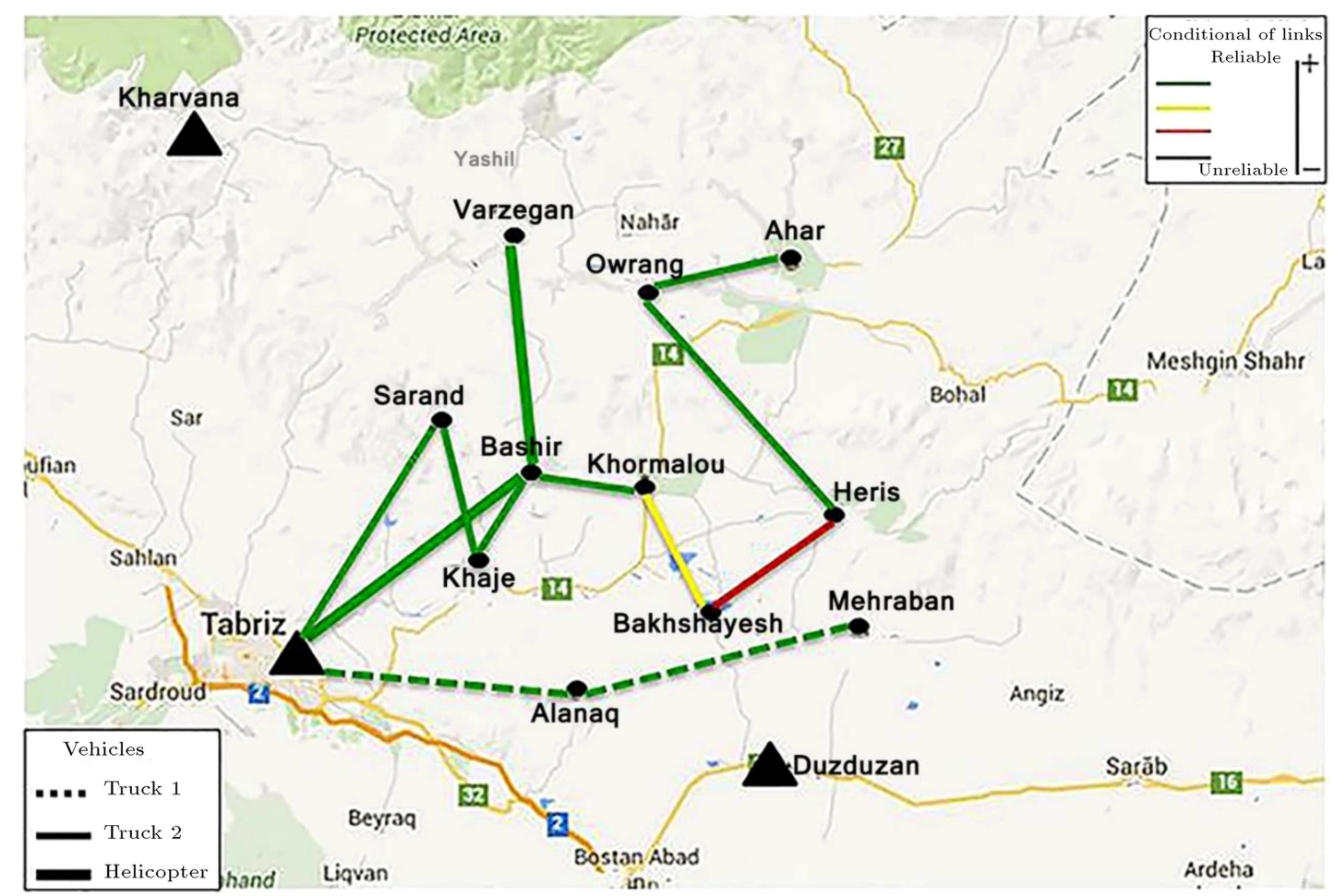

Figure 3. Transportation network in uncertainty condition.

shown under both certainty and uncertainty conditions in Tables 2 and 3 at different levels and different degrees of importance for the objective functions. The tests are conducted under three levels of uncertainty $(\rho=0.3,0.5$, and 0.7$)$. Also, the level of un- certainty in each test problem has been considered the same for all parameters. For the problems, the parameters and required information were generated based on the data and information gathered for the studied earthquake. As shown in Table 3, all un- 
Table 2. Demand fill rate (\%).

\begin{tabular}{ccc}
\hline $\begin{array}{c}\text { Demand } \\
\text { points }\end{array}$ & Deterministic & Robust \\
\hline Khormalou $i_{1}$ & 81 & 57 \\
Varzeqan $i_{2}$ & 95 & 100 \\
Bakhshayesh $i_{3}$ & 81 & 80 \\
Mehraban $i_{4}$ & 92 & 75 \\
Ahar $i_{5}$ & 100 & 100 \\
Heris $i_{6}$ & 100 & 100 \\
Khaje $i_{7}$ & 100 & 100 \\
Alanaq $i_{8}$ & 76 & 56 \\
Owrang $i_{9}$ & 100 & 100 \\
Sarand $i_{10}$ & 87 & 82 \\
Bashir $i_{11}$ & 100 & 95 \\
\hline
\end{tabular}

certainty problems have answers worse than certainty ones, because in the robust optimization approach, we consider the worst situation until in action, we face the lowest harm and risk. In addition, with regard to Table 4 , it can be concluded that $\mathrm{TH}$ method obtains exclusive solutions for every degree of importance for the objective functions. In total, it can be concluded that $\mathrm{TH}$ method is an appropriate and eligible way for multi-objective programming problems because it is able to obtain more efficient and effective results.

In problem no. 1 , the impact of the penalty rate

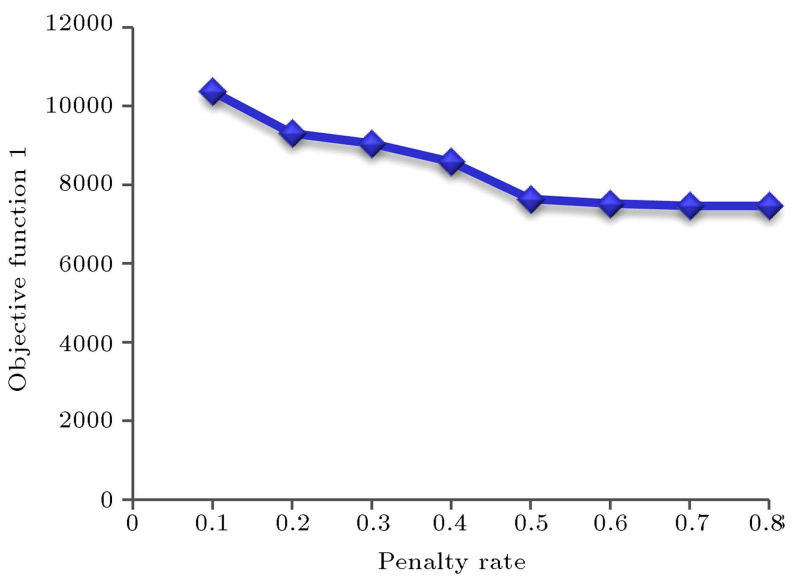

Figure 4. Objective function (1) and penalty rate.

$(\psi)$ on objective functions has been investigated under certainty and uncertainty conditions. For this purpose, 8 experiments with different penalty rates in the range of $0.1-0.8$ were generated and analyzed. As can be seen in Table 5 and Figures 4-6, balanced and imbalanced solutions to a problem were obtained based on the decision-maker's preferences with $\theta=(0.3,0.3,0.4)$ via setting the parameter $\psi$. The results indicated that balanced solutions were produced for the values of $\psi$ between $0.4-0.6$ for the problem.

In Table 6 , given $\rho=0.3$ and $\theta=(0.3,0.3,0.4)$ for each problem in certainty and robust cases, the established DC, the route for any vehicle, and the values of functions are provided, separately.

Table 3. Sensitivity analysis of the level of uncertainty $(\rho)$ given that $\psi=0.4$.

\begin{tabular}{|c|c|c|c|c|c|c|c|c|c|}
\hline \multirow{2}{*}{$\begin{array}{c}\text { Test } \\
\text { problem }\end{array}$} & \multicolumn{6}{|c|}{ Deterministic } & \multicolumn{3}{|c|}{ Robust } \\
\hline & $n$ & $m h g$ & $\left(z_{1}, \mu_{1}\right)$ & $\left(z_{2}, \mu_{2}\right)$ & $\left(z_{3}, \mu_{3}\right)$ & $\rho$ & $\left(z_{1}, \mu_{1}\right)$ & $\left(z_{2}, \mu_{2}\right)$ & $\left(z_{3}, \mu_{3}\right)$ \\
\hline 1 & 11 & 312 & $(8583.5,0.69)$ & $(16,0.72)$ & $(0.81,0.74)$ & $\begin{array}{l}0.3 \\
0.5 \\
0.7\end{array}$ & $\begin{array}{l}(11710.79,0.65) \\
(16901.85,0.90) \\
(23002.36,0.89)\end{array}$ & $\begin{array}{l}(18.08,0.63) \\
(17.96,0.53) \\
(19.21,0.55)\end{array}$ & $\begin{array}{c}(0.805,0.67) \\
(0.77,0.59) \\
(0.652,0.62)\end{array}$ \\
\hline 2 & 10 & 422 & $(12639.7,0.64)$ & $(9.74,0.66)$ & $(0.90,0.85)$ & $\begin{array}{l}0.3 \\
0.5 \\
0.7\end{array}$ & $\begin{array}{l}(18331.37,0.28) \\
(21713.40,0.37) \\
(18614.83,0.90)\end{array}$ & $\begin{array}{l}(10.70,0.61) \\
(13.44,0.46) \\
(13.48,0.85)\end{array}$ & $\begin{array}{l}(0.90,0.85) \\
(0.80,0.75) \\
(0.73,0.54)\end{array}$ \\
\hline 3 & 8 & 212 & $(3794.2,0.62)$ & $(5.43,0.64)$ & $(0.95,0.92)$ & $\begin{array}{l}0.3 \\
0.5 \\
0.7\end{array}$ & $\begin{array}{l}(4287.14,0.65) \\
(4528.65,0.64) \\
(5017.89,0.62)\end{array}$ & $\begin{array}{l}(4.87,0.69) \\
(4.87,0.69) \\
(5.11,0.67)\end{array}$ & $\begin{array}{c}(0.95,0.89) \\
(0.85,0.75) \\
(0.73,0.58)\end{array}$ \\
\hline 4 & 6 & $\begin{array}{lll}3 & 13\end{array}$ & $(3124.7,0.63)$ & $(3.56,0.65)$ & $(0.90,0.87)$ & $\begin{array}{l}0.3 \\
0.5 \\
0.7\end{array}$ & $\begin{array}{c}(4211.09,0.59) \\
(5017.5,0.60) \\
(5088.27,0.67)\end{array}$ & $\begin{array}{l}(3.96,0.64) \\
(3.37,0.70) \\
(4.10,0.62)\end{array}$ & $\begin{array}{c}(0.855,0.83) \\
(0.89,0.95) \\
(0.85,0.88)\end{array}$ \\
\hline 5 & 12 & 524 & $(19746.3,0.74)$ & $(21.6,0.71)$ & $(0.93,0.90)$ & $\begin{array}{l}0.3 \\
0.5 \\
0.7\end{array}$ & $\begin{array}{c}(25851.2,0.59) \\
(27489.41,0.63) \\
(32678.10 .0 .53)\end{array}$ & $\begin{array}{l}(23.4,0.63) \\
(22.94,0.58) \\
(24.54 .0 .65)\end{array}$ & $\begin{array}{l}(0.90,0.90) \\
(0.76,0.84) \\
(0.72 .0 .78)\end{array}$ \\
\hline
\end{tabular}


Table 4. The results of the sensitivity analysis of $\theta$-value for the problems given that $\rho=0.3$ and $\psi=0.4$.

\begin{tabular}{|c|c|c|c|c|c|c|c|}
\hline \multirow{2}{*}{$\begin{array}{c}\text { Test } \\
\text { problem }\end{array}$} & \multirow{2}{*}{$\theta_{1}, \theta_{2}, \theta_{3}$} & \multicolumn{3}{|c|}{ Deterministic } & \multicolumn{3}{|c|}{ Robust } \\
\hline & & $\left(z_{1}, \mu_{1}\right)$ & $\left(z_{2}, \mu_{2}\right)$ & $\left(z_{3}, \mu_{3}\right)$ & $\left(z_{1}, \mu_{1}\right)$ & $\left(z_{2}, \mu_{2}\right)$ & $\left(z_{3}, \mu_{3}\right)$ \\
\hline \multirow{4}{*}{1} & $(0.3,0.3,0.4)$ & $(8583.5,0.69)$ & $(16,0.72)$ & $(0.81,0.74)$ & $(11710.79,0.65)$ & $(18.08,0.63)$ & $(0.805,0.67)$ \\
\hline & $(0.3,0.4,0.3)$ & $(9438.3,0.83)$ & $(15.16,0.86)$ & $(0.79,0.71)$ & $(14297.23,0.62)$ & $(17.05,0.72)$ & $(0.80,0.66)$ \\
\hline & $(0.4,0.3,0.3)$ & $(8152.8,0.94)$ & $(16.44,0.76)$ & $(0.80,0.72)$ & $(9993.91,0.92)$ & $(19.96,0.48)$ & $(0.79,0.65)$ \\
\hline & $(0.2,0.4,0.4)$ & $(10322.5,0.68)$ & $(15.08,0.86)$ & $(0.847,0.87)$ & $(13549.49,0.69)$ & $(17.05,0.72)$ & $(0.82$, \\
\hline \multirow{4}{*}{2} & $(0.3$ & $(1263$ & 66) & $(0.9$ & (1833 & $(10$ & $(0.90$ \\
\hline & $(0.3,0.4,0.3)$ & $(12047.2,0.84)$ & $(7.67,0.83)$ & $(0.827,0.74)$ & $(19282.9,0.16)$ & $(10.23,0.65)$ & $(0.805,0.72)$ \\
\hline & $(0.4,0.3,0.3)$ & $(11947.8,0.87)$ & $(9.2,0.70)$ & $(0.76,0.64)$ & $(14781.7,0.63)$ & $(11.46,0.54)$ & $(0.72,0.58)$ \\
\hline & $(0.2,0.4,0$. & $(12096.5,0.82)$ & $(7.25,0.82)$ & $(0.79,0.71)$ & $(19156.2,0.18)$ & $(9.98,0.67)$ & $(0.78,0.67)$ \\
\hline \multirow{4}{*}{3} & $(0 .:$ & $(37$ & $(5.43,0$ & $(0.9$ & $\left(428^{\prime}\right.$ & $(4.8$ & $(0.9$ \\
\hline & $(0.3$ & $(380$ & $(4.28$ & $(0.95,0$. & $(4946.5,0.36)$ & $(4.40,0.74)$ & $(0.855,0.69)$ \\
\hline & $(0.4$, & $(36$ & $(4.89,0.70)$ & $(0.855,0$. & $(3858.53,0.82)$ & $(5.35,0.65)$ & $(0.812,0.60)$ \\
\hline & $(0.2,0.4,0.4)$ & $4.15,0.54)$ & $3,0.76)$ & $(0.95,0.92)$ & $(5421.41,0.34)$ & $(4.04,0.81)$ & $(0.90,0.78)$ \\
\hline \multirow{4}{*}{4} & $(0.3,0.3,0.4)$ & $(3124.7,0.63)$ & $(3.56,0.65)$ & $(0.90,0$ & $09,0.59)$ & $(3.96,0.64)$ & $(0.8$ \\
\hline & $(0.3,0.4,0.3)$ & $(3322.3,0.58)$ & $(1.75,0.87)$ & $(0.85,0.74)$ & $(5016.31,0.48)$ & $(2.26,0.86)$ & $(0.85,0.73)$ \\
\hline & $(0.4,0.3,0.3)$ & $(2761.3,0.72)$ & $(2.43,0.78)$ & $(0.90,0.87)$ & $(3864.19,0.64)$ & $(2.92,0.77)$ & $(0.81,0.71)$ \\
\hline & $(0.2,0.4,0.4)$ & $(3633.9,0.51)$ & $(2.517,0.77)$ & $(0.90,0.87)$ & $(5261.75,0.45)$ & $(3.15,0.75)$ & $(0.85,0.73)$ \\
\hline \multirow{4}{*}{. } & $(0 .:$ & (1) & $(21.6,0.71)$ & $(0.9$ & $2,0.59)$ & $(23.4,0.63)$ & $(0.90,0.90)$ \\
\hline & $(0.3,0.4,0.3)$ & $(24461,0.52)$ & $(18.4,0.89)$ & $(0.87,0.83)$ & $(29140.02,0.36)$ & $(19.8,0.86)$ & $(0.855,0.81)$ \\
\hline & $(0.4,0.3,0.3)$ & $(18754.1,0.80)$ & $(19,0.85)$ & $(0.75,0.67)$ & $(21154.1,0.73)$ & $(20.9,0.81)$ & $(0.75,0.67)$ \\
\hline & $(0.2,0.4,0.4)$ & $(23150,0.58)$ & $(17.9,0.91)$ & $(0.80,0.73)$ & $(27454.21,0.44)$ & $(19.5,0.88)$ & $(0.79,0.71)$ \\
\hline
\end{tabular}

Table 5. Results of sensitivity analysis of $\varphi$-value for the problems based on the $\rho=0.3$ and $\theta=(0.3,0.3,0.4)$.

\begin{tabular}{cccccccc}
\hline \multirow{2}{*}{$\begin{array}{c}\text { Test } \\
\text { problem }\end{array}$} & $\boldsymbol{\psi}$ & \multicolumn{3}{c}{ Deterministic } & \multicolumn{3}{c}{ Robust } \\
\cline { 2 - 8 } & & $\left(\boldsymbol{z}_{\mathbf{1}}, \boldsymbol{\mu}_{\mathbf{1}}\right)$ & $\left(\boldsymbol{z}_{\mathbf{2}}, \boldsymbol{\mu}_{\mathbf{2}}\right)$ & $\left(\boldsymbol{z}_{\mathbf{3}}, \boldsymbol{\mu}_{\mathbf{3}}\right)$ & $\left(\boldsymbol{z}_{\mathbf{1}}, \boldsymbol{\mu}_{\mathbf{1}}\right)$ & $\left(\boldsymbol{z}_{\mathbf{2}}, \boldsymbol{\mu}_{\mathbf{2}}\right)$ & $\left(\boldsymbol{z}_{\mathbf{3}}, \boldsymbol{\mu}_{\mathbf{3}}\right)$ \\
\hline 1 & 0.1 & $(10369.3,0.64)$ & $(13.57,0.98)$ & $(0.90,0.86)$ & $(14842.1,0.58)$ & $(15.78,0.81)$ & $(0.87,0.78)$ \\
2 & 0.2 & $(9309.2,0.57)$ & $(15.04,0.86)$ & $(0.855,0.79)$ & $(13145.35,0.61)$ & $(16.9,0.72)$ & $(0.83,0.72)$ \\
3 & 0.3 & $(9048.1,0.65)$ & $(15.27,0.80)$ & $(0.855,0.79)$ & $(13687.51,0.64)$ & $(17.38,0.68)$ & $(0.83,0.72)$ \\
4 & 0.4 & $(8583.5,0.69)$ & $(16,0.72)$ & $(0.81,0.74)$ & $(11710.79,0.65)$ & $(18.08,0.63)$ & $(0.805,0.67)$ \\
5 & 0.5 & $(7635.1,0.69)$ & $(16.27,0.72)$ & $(0.77,0.74)$ & $(10456.7,0.65)$ & $(18.58,0.63)$ & $(0.68,0.67)$ \\
6 & 0.6 & $(7517,0.69)$ & $(16.61,0.72)$ & $(0.72,0.74)$ & $(9852,0.65)$ & $(19.03,0.62)$ & $(0.61,0.67)$ \\
7 & 0.7 & $(7461.7,0.71)$ & $(17.83,0.71)$ & $(0.70,0.73)$ & $(9614.72,0.67)$ & $(19.96,0.60)$ & $(0.58,0.68)$ \\
\hline
\end{tabular}

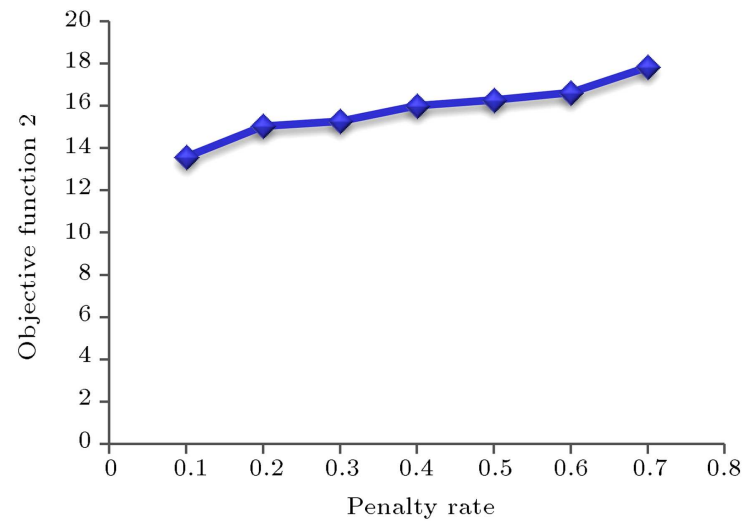

Figure 5. Objective function (2) and penalty rate.

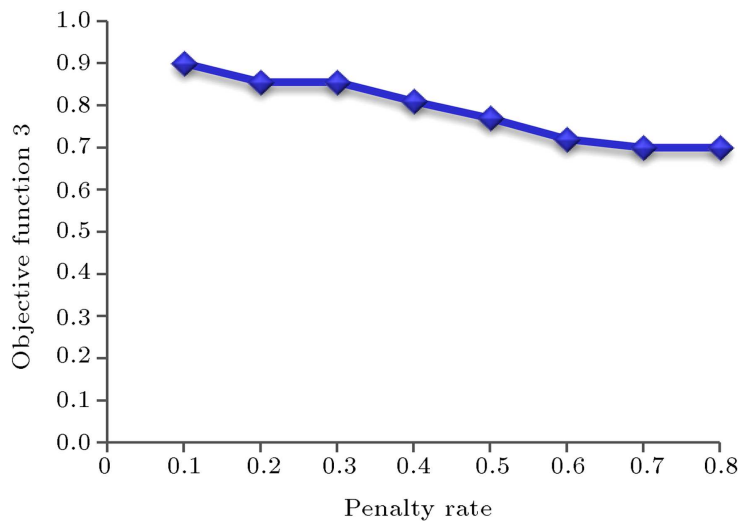

Figure 6. Objective function (3) and penalty rate. 
D. Veysmoradi et al./Scientia Iranica, Transactions E: Industrial Engineering 25 (2018) 3635-3653

Table 6. Detailed results for each problem.

\begin{tabular}{|c|c|c|c|c|c|c|c|c|}
\hline & $\begin{array}{c}\text { Test } \\
\text { problem }\end{array}$ & DCs & Vehicle & Route & $\begin{array}{c}\text { Location } \\
\text { cost }\end{array}$ & $\begin{array}{c}\text { Routing } \\
\text { cost }\end{array}$ & $\begin{array}{c}\text { Min-max } \\
\text { routing time }\end{array}$ & $\begin{array}{c}\text { Max-min } \\
\text { routing reliability }\end{array}$ \\
\hline \multirow{5}{*}{. } & 1 & 13 & $\begin{array}{l}h_{1} \\
g_{1} \\
g_{2}\end{array}$ & $\begin{array}{c}13-6 \\
13-4-11-1-10-7 \\
13-3-8-7-11-5-9-2\end{array}$ & 1500 & 7083.5 & 16 & 0.81 \\
\hline & 2 & 13 & $\begin{array}{l}h_{1} \\
h_{2} \\
g_{1} \\
g_{2}\end{array}$ & $\begin{array}{c}13-4-8-7 \\
13-10 \\
13-2-6-10 \\
13-3-1-9-5\end{array}$ & 2500 & 10139.7 & 9.744 & 0.90 \\
\hline & 3 & 9 & $\begin{array}{l}h_{1} \\
g_{1} \\
g_{2}\end{array}$ & $\begin{array}{c}9-8-4 \\
9-6-2-5-7 \\
9-1-3\end{array}$ & 1200 & 2594.20 & 5.43 & 0.95 \\
\hline & 4 & 9 & $\begin{array}{l}h_{1} \\
g_{1} \\
g_{2} \\
g_{3}\end{array}$ & $\begin{array}{c}9-4 \\
9-1-2-6-3 \\
9-2 \\
9-5\end{array}$ & 1500 & 1624.7 & 3.56 & 0.90 \\
\hline & 5 & 14,16 & $\begin{array}{l}h_{1} \\
h_{2} \\
g_{1} \\
g_{2} \\
g_{3} \\
g_{4}\end{array}$ & $\begin{array}{c}16-4-12-5 \\
14-3 \\
14-10-8 \\
16-6-1-9-2 \\
16-7-10-11 \\
16-8-2\end{array}$ & 7500 & 12246.3 & 21.6 & 0.93 \\
\hline \multirow{5}{*}{$\begin{array}{l}\overrightarrow{0} \\
\overrightarrow{0} \\
\overrightarrow{0} \\
\dot{n}\end{array}$} & 1 & 14 & $\begin{array}{l}h_{1} \\
g_{1} \\
g_{2}\end{array}$ & $\begin{array}{c}14-11-2 \\
14-8-4 \\
14-10-7-11-1-3 \\
-6-9-5\end{array}$ & 2000 & 9710.79 & 18.08 & 0.805 \\
\hline & 2 & 14 & $\begin{array}{l}h_{1} \\
h_{2} \\
g_{1}\end{array}$ & $\begin{array}{c}14-4-2-1-6 \\
14-8 \\
14-3-5 \\
14-5-9-10-7\end{array}$ & 3900 & 14431.37 & 10.70 & 0.90 \\
\hline & 3 & 9 & $\begin{array}{l}g_{2} \\
h_{1} \\
g_{1} \\
g_{2} \\
h_{1}\end{array}$ & $\begin{array}{c}9-8-2 \\
9-5-7-1 \\
9-4-2-6-3\end{array}$ & 1560 & 2727.14 & 4.871 & 0.95 \\
\hline & 4 & 7 & $\begin{array}{l}h_{1} \\
g_{1} \\
g_{2} \\
g_{3}\end{array}$ & $\begin{array}{c}7-6 \\
7-2-6-3 \\
7-5 \\
7-1-2-4\end{array}$ & 750 & 3461.09 & 3.96 & 0.855 \\
\hline & 5 & 13,17 & $\begin{array}{l}h_{1} \\
h_{2} \\
g_{1} \\
g_{2} \\
g_{3} \\
g_{4}\end{array}$ & $\begin{array}{c}13-5-9 \\
17-2 \\
17-1-8-3 \\
13-4-8-7-11 \\
17-6-3-10 \\
17-12-11-10-7\end{array}$ & 11300 & 14551.2 & 23.4 & 0.90 \\
\hline
\end{tabular}




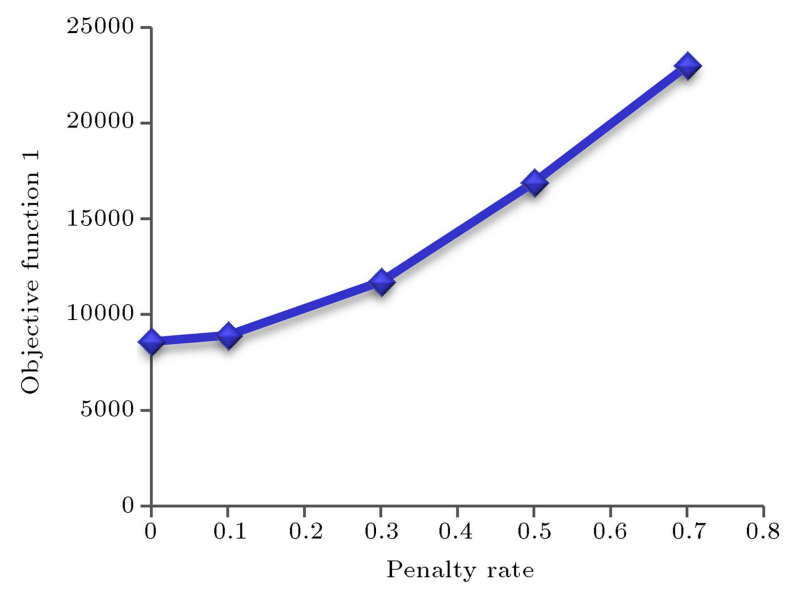

Figure 7. Objective function (1) and uncertainty level.

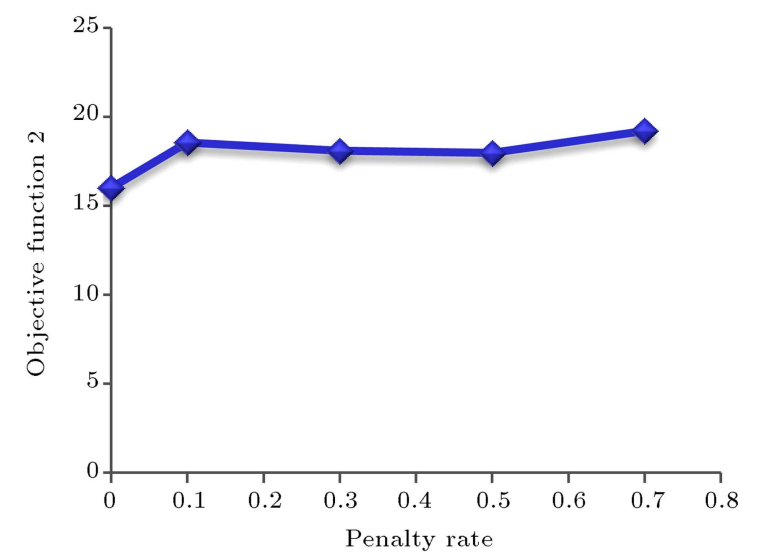

Figure 8. Objective function (2) and uncertainty level.

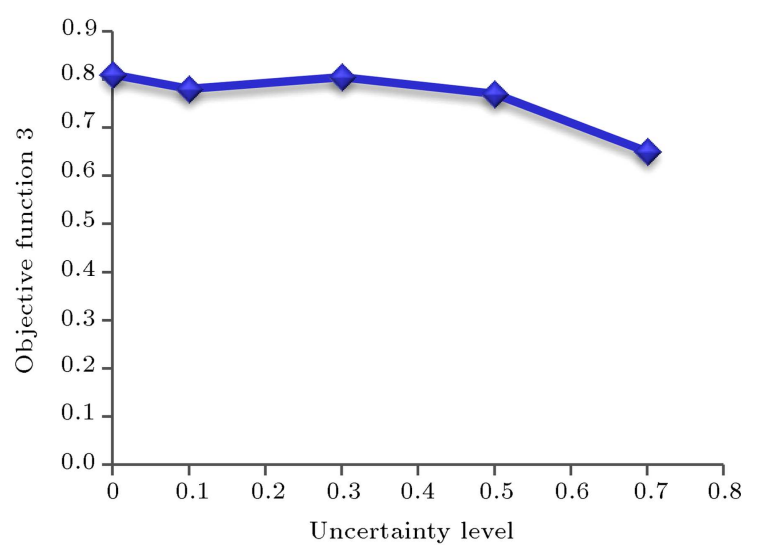

Figure 9. Objective function (3) and uncertainty level.

In Figures 7-9, sensitivity analysis of the level of uncertainty for the objective function is depicted, in which, using the data related to problem 1 , different levels of uncertainty have been investigated. As it is shown, it cannot be said that the relationship between the level of uncertainty and the objective function is a direct one. A sensitivity analysis of the efficiency of the model and grade of the penetration of parameters in the model has been carried out to validate it more. As

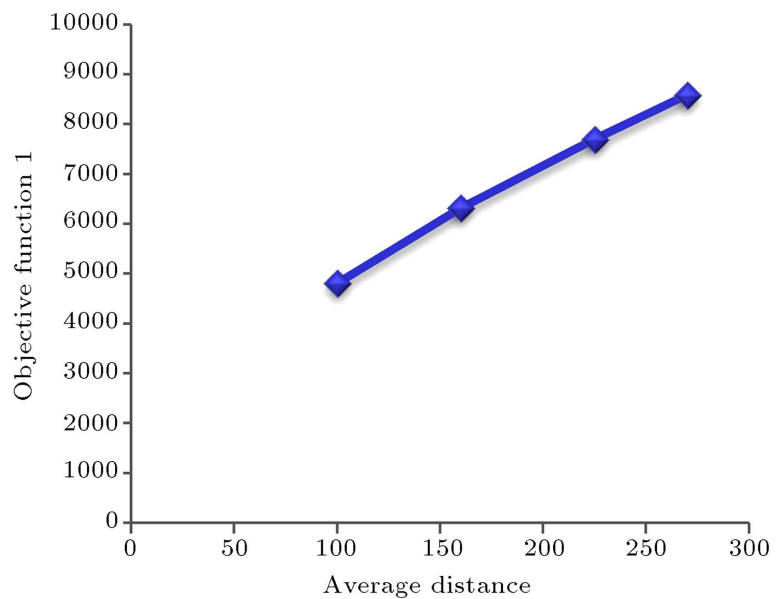

Figure 10. Objective function (1) and average distance.

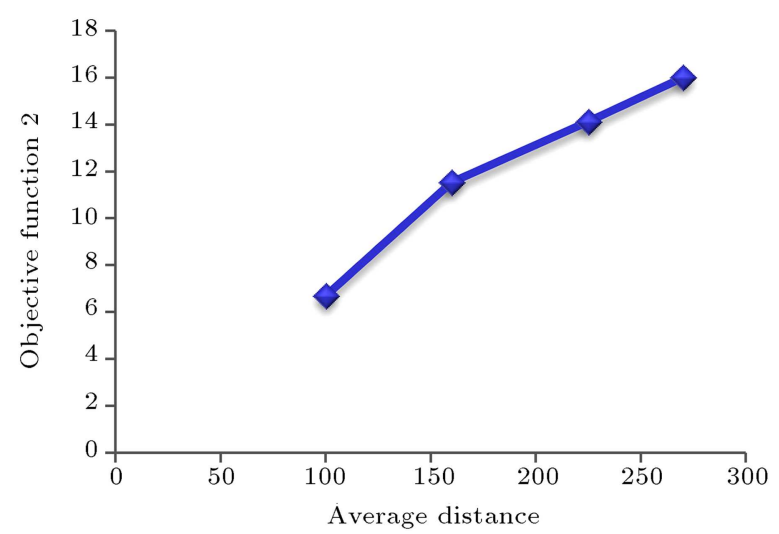

Figure 11. Objective function (2) and average distance.

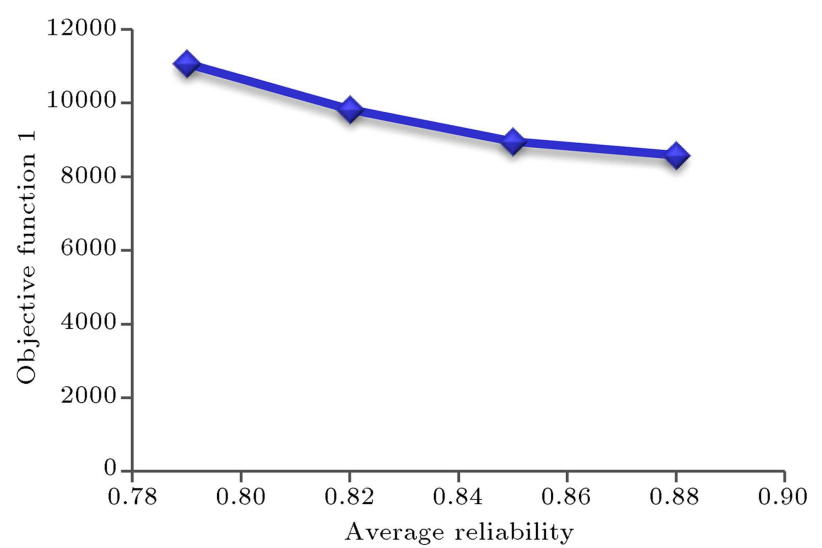

Figure 12. Objective function (1) and average reliability.

it can be seen in Figures 10 and 11, with an increase in the mean distance, the value of the objective function also increases.

Another effective parameter in the model is reliability of any connection that is different for air and ground transportation networks. As can be seen in Figures 12-14, cost increases by reducing the reliability, but travel time and reliability for the entire route decrease. 


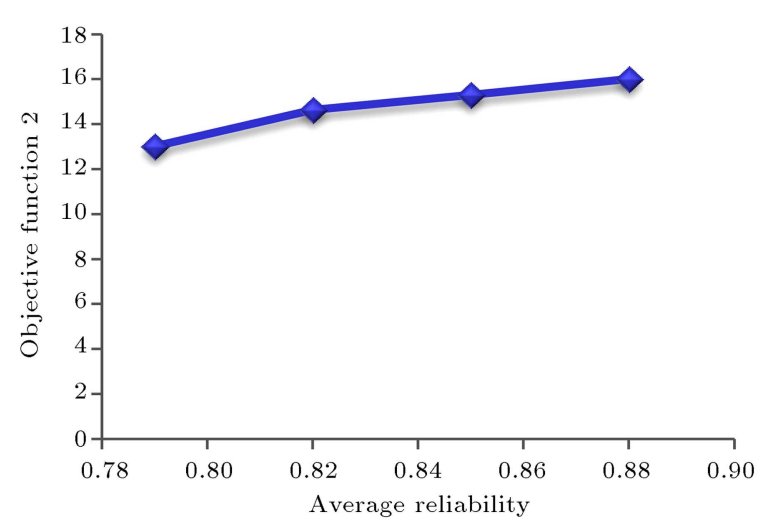

Figure 13. Objective function (2) and average reliability.

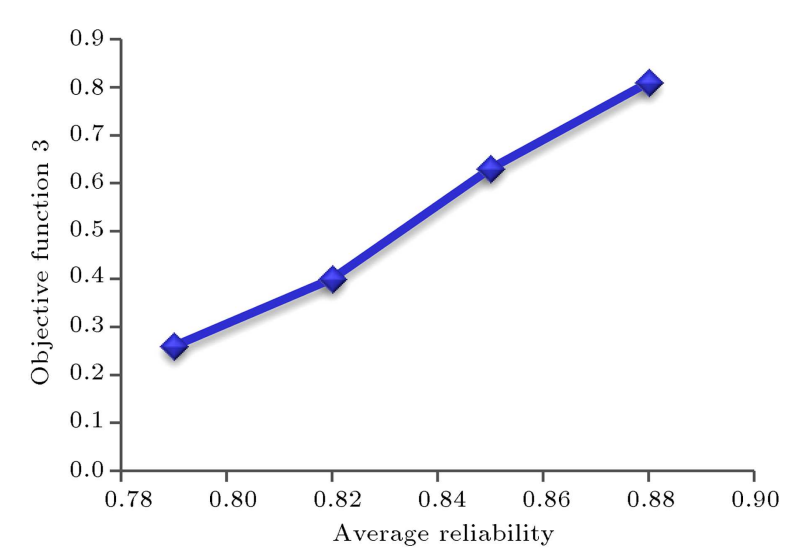

Figure 14. Objective function (3) and average reliability.

\section{Conclusion and future research}

In this study, a mixed-integer nonlinear open locationrouting model for the delivery of aid after the earthquake with multiple objectives including the time travel, the total cost, and reliability was presented. Then, using a robust optimization approach, the proposed model was developed in uncertainty conditions. Finally, the proposed model was solved using fuzzy multi-objective programming. For the performance of the model, a case study of East Azarbaijan earthquake was presented and the certainty and uncertainty results were compared with each other. According to the obtained results, it was concluded that the proposed model could be an effective and valid methodology to manage relief distribution in an uncertain condition. Also, the time solution for the proposed model in either certain or uncertain state was reasonable for small sizes.

In the future research, the model can also be considered as a multi-period one with regard to repairing the damaged roads. Also, in addition to carrying essential goods to the earthquake stricken areas, the discharge evacuation of the injured people from these locations and their transfer to emergency units can be considered in the model. Since locationrouting problems are NP-hard, a variety of solutions to meta-heuristic algorithms can be considered for future research.

\section{References}

1. Bozorgi-Amiri, A. Jabalameli, M.S., Alinaghian, M., and Heydari, M. "A modified particle swarm optimization for disaster relief logistics under uncertain environment" , The International Journal of Advanced Manufacturing Technology, 60(1), pp. 357-371 (2012).

2. Fawu, W., QianGong, C., Highland, L., Miyajima, M., HuaBin, W., and ChangGen, Y. Preliminary Investigation of Some Large Landslides Triggered by the 2008 Wenchuan Earthquake, Sichuan Province, China. Landslides, 6(1), pp. 47-54 (2009).

3. Qiang, P., and Nagurney, A. "A bi-criteria indicator to assess supply chain network performance for critical needs under capacity and demand disruptions", Transportation Research Part A: Policy and Practice, 46(5), pp. 801-812 (2012).

4. Menezes, M.B., Ruiz-Hernández, D., and Verter, V. "A rough-cut approach for evaluating location-routing decisions via approximation algorithms", Transportation Research Part B: Methodological, 87, pp. 89-106 (2016).

5. Vahdani, B., Veysmoradi, D., Shekari, N., and Mousavi, S.M. "Multi-objective, multi-period locationrouting model to distribute relief after earthquake by considering emergency roadway repair", Neural Computing and Applications, 30(3), pp. 835-854 (2018).

6. Toro, E., Franco, J., Echeverri, M., Guimares, F., and Rendãn, R. "Green open location-routing problem considering economic and environmental costs", International Journal of Industrial Engineering Computations, 8(2), pp. 203-216 (2017).

7. Qiu, H. and Zhang, X. "Research on open location routing problem based on improved particle swarm optimization algorithm", Zhongguo Jixie Gongcheng/China Mechanical Engineering, 17(22), pp. 2359-2361 (2006).

8. Chang, K. Zhou, H. Chen, G., and Chen, H. "Multi-objective Location Routing Problem considering Uncertain Data after Disasters", Discrete Dynamics in Nature and Society, (2017). https://www.hindawi.com/journals/ddns/2017/1703608/

9. Archetti, C. Savelsbergh, M.W., and Speranza, M.G. "To split or not to split: That is the question", Transportation Research Part E: Logistics and Transportation Review, 44(1), pp. 114-123 (2008).

10. Wang, H. Du, L., and Ma, S. "Multi-objective open location-routing model with split delivery for optimized relief distribution in post-earthquake", Transportation Research, Part E: Logistics and Transportation Review, 69, pp. 160-179 (2014).

11. Bozorgi-Amiri, A., Jabalameli, M.S., and Mirzapour Al-e-Hashem, S.M. "A multi-objective robust stochastic programming model for disaster relief logistics under uncertainty", OR Spectrum, 35(4), pp. 905-933 (2013). 
12. Akkihal, A.R. "Inventory pre-positioning for humanitarian operations", Doctoral Dissertation, Massachusetts Institute of Technology, MIT (2006).

13. Tzeng, G.H., Cheng, H.J., and Huang, T.D. "Multiobjective optimal planning for designing relief delivery systems", Transportation Research Part E: Logistics and Transportation Review, 43(6), pp. 673-686 (2007).

14. Rajagopalan, H.K., Saydam, C., and Xiao, J. "A multiperiod set covering location model for dynamic redeployment of ambulances", Computers \& Operations Research, 35(3), pp. 814-826 (2008).

15. Balcik, B. and Beamon, B.M. "Facility location in humanitarian relief", International Journal of Logistics, 11(2), pp. 101-121 (2008).

16. Vitoriano, B. Ortuño, M.T. Tirado, G., and Montero, J. "A multi-criteria optimization model for humanitarian aid distribution", Journal of Global optimization, 51(2), pp. 189-208 (2011).

17. Ozdamar, L. "Planning helicopter logistics in disaster relief", OR Spectrum, 33(3), pp. 655-672 (2011).

18. Özdamar, L. and Demir, O. "A hierarchical clustering and routing procedure for large scale disaster relief logistics planning", Transportation Research Part E: Logistics and Transportation Review, 48(3), pp. 591602 (2012).

19. Talarico, L. Meisel, F., and Sörensen, K. "Ambulance routing for disaster response with patient groups", Computers \& Operations Research, 56, pp. 120-133 (2015).

20. Fiedrich, F. Gehbauer, F., and Rickers, U. "Optimized resource allocation for emergency response after earthquake disasters", Safety science, 35(1), pp. 41-57 (2000).

21. Barbarosoğlu, G. and Arda, Y. "A two-stage stochastic programming framework for transportation planning in disaster response", Journal of the Operational Research Society, 55(1), pp. 43-53 (2004).

22. Yi, W. and Özdamar, L. "A dynamic logistics coordination model for evacuation and support in disaster response activities", European Journal of Operational Research, 179(3), pp. 1177-1193 (2007).

23. Yi, W. and Kumar, A. "Ant colony optimization for disaster relief operations", Transportation Research Part E: Logistics and Transportation Review, 43(6), pp. 660-672 (2007).

24. Setiawan, E. and French A.P. "A location-Allocation model for relief distribution and victim evacuation proceeding", International Seminar on Industrial Engineering and Management (2009).

25. Eshghi, K. and Najafi, M. "A logistics planning model to improve the response phase of earthquake", International Journal of Industrial Engineering, 23(4), pp. 401-416 (2013).

26. Rath, S. and Gutjahr, W.J. "A math-heuristic for the warehouse location-routing problem in disaster relief", Computers \& Operations Research, 42, pp. 2539 (2014).
27. Bozorgi-Amiri, A. and Khorsi, M. "A dynamic multiobjective location-routing model for relief logistic planning under uncertainty on demand, travel time, and cost parameters", The International Journal of Advanced Manufacturing Technology, 85(5-8), pp. 16331648 (2016).

28. Zokaee, S. Bozorgi-Amiri, A., and Sadjadi, S.J. "A robust optimization model for humanitarian relief chain design under uncertainty", Applied Mathematical Modelling, 40(17), pp. 7996-8016 (2016).

29. Ben-Tal, A., El-Ghaoui, L., and Nemirovski, A. Robust Optimization, Princeton University, Press (2009).

30. Torabi, S.A. and Hassini, E. "An interactive possibilistic programming approach for multiple objective supply chain master planning", Fuzzy Sets and Systems, 159(2), pp. 193-214 (2008).

31. Vahdani, B. Tavakkoli-Moghaddam, R. Modarres, M., and Baboli, A. "Reliable design of a forward/reverse logistics network under uncertainty: a robust-M/M/c queuing model", Transportation Research, Part E: Logistics and Transportation Review, 48(6), pp. 11521168 (2012).

32. Ben-Tal, A., Nemirovsky A. "Robust solutions of uncertain linear programs", Operations Research Letters, 25(1), pp. 1-13 (1999).

33. Zimmermann, H.J. "Fuzzy programming and linear programming with several objective functions", Fuzzy Sets and Systems, 1(1), pp. 45-55 (1978).

34. Lai, Y.J. and Hwang, C.L. "Possibilistic linear programming for managing interest rate risk", Fuzzy Sets and Systems, 54(2), pp. 135-146 (1993).

35. Mahapatra, G.S. and Roy, T.K. "Fuzzy multi-objective mathematical programming on reliability optimization model", Applied Mathematics and Computation, 174(1), pp. 643-659 (2006).

36. Islam, S. and Roy, T.K. "A new fuzzy multi-objective programming: Entropy based geometric programming and its application of transportation problems", European Journal of Operational Research, 173(2), pp. 387-404 (2006).

37. Selim, H. and Ozkarahan, I. "A supply chain distribution network design model: an interactive fuzzy goal programming-based solution approach", The International Journal of Advanced Manufacturing Technology, 36(3), pp. 401-418 (2008).

38. Werners, B.M. "Aggregation models in mathematical programming", In Mathematical Models for Decision Support, pp. 295-305, Springer Berlin Heidelberg (1988).

39. Li, X.Q., Zhang, B., and Li, H. "Computing efficient solutions to fuzzy multiple objective linear programming problems", Fuzzy Sets and Systems, 157(10), pp. 1328-1332 (2006).

\section{Appendix}

The information is provided in Tables A.1 to A.4. 
Table A.1. Candidate DC parameters.

\begin{tabular}{cc}
\hline $\begin{array}{c}\text { Name of candidate } \\
\text { DC }_{\mathbf{s}}\end{array}$ & Fixed cost $\boldsymbol{f}_{\boldsymbol{j}}(\mathbf{\$})$ \\
\hline Kharvana, $j_{12}$ & 10000 \\
Duzduzan, $j_{13}$ & 15000 \\
Tabriz, $j_{14}$ & 20000 \\
\hline
\end{tabular}

Table A.2. Parameters of relief commodity.

\begin{tabular}{ccc}
\hline Item & $\begin{array}{c}\text { Available } \\
\text { quantity } \\
\boldsymbol{Q}_{\boldsymbol{l}}\end{array}$ & $\begin{array}{c}\text { Volume } \\
\text { of unit } \\
\mathbf{c}\left(\mathbf{c m}^{\mathbf{3}}\right)\end{array}$ \\
\hline Mineral water & 35000 & $45 \times 25 \times 11$ \\
Tent & 12000 & $36 \times 26 \times 30$ \\
\hline
\end{tabular}

Table A.3. Parameters of the vehicles.

\begin{tabular}{cccc}
\hline $\begin{array}{c}\text { Vehicle } \\
\text { name }\end{array}$ & $\begin{array}{c}\text { Loading } \\
\text { capacity } \\
\left(\mathbf{c m}^{\mathbf{3}}\right)\end{array}$ & $\begin{array}{c}\text { Normal } \\
\text { velocity } \\
(\mathbf{k m} / \mathbf{h})\end{array}$ & $\begin{array}{c}\text { Cost per } \\
\text { unit of } \\
\text { length } \mathbf{( \$ )}\end{array}$ \\
\hline Helicopter 1 & $750 \times 330 \times 280$ & 120 & 10 \\
Truck 1 & $580 \times 260 \times 190$ & 100 & 3.1 \\
Truck 2 & $630 \times 280 \times 200$ & 85 & 1.7 \\
\hline
\end{tabular}

Table A.4. Parameters of the disaster areas.

\begin{tabular}{lc}
\hline Demand points & Demands $\left(\boldsymbol{D}_{\boldsymbol{i} \mathbf{1}}, \boldsymbol{D}_{\boldsymbol{i} \mathbf{2}}\right)$ \\
\hline Khormalou $i_{1}$ & $(2100,700)$ \\
Varzeqan $i_{2}$ & $(2400,800)$ \\
Bakhshayesh $i_{3}$ & $(960,323)$ \\
Mehraban $i_{4}$ & $(1500,515)$ \\
Ahar $i_{5}$ & $(818,273)$ \\
Heris $i_{6}$ & $(430,146)$ \\
Khaje $i_{7}$ & $(1300,449)$ \\
Alanaq $i_{8}$ & $(2700,900)$ \\
Owrang $i_{9}$ & $(600,200)$ \\
Sarand $i_{10}$ & $(1000,400)$ \\
Bashir $i_{11}$ & $(900,300)$ \\
\hline
\end{tabular}

\section{Biographies}

Donya Veysmoradi is currently MS student in the Department of Industrial Engineering at Qazvin Branch, Islamic Azad University, Qazvin, Iran. Her research interests include applied operations research.

Behnam Vahdani is an Assistant Professor at Faculty of Industrial and Mechanical Engineering, Qazvin Branch, Islamic Azad University in Iran, and is a member of Iran's National Elite Foundation. His current research interests include: Supply chain network design, facilities planning and design, multi-criteria decision making, uncertain programming, artificial neural networks, meta-heuristics algorithms and operations research applications. He has published numerous papers and book chapters in the aforementioned areas.

Morteza Farhadi Sartangi is an instructor at department of industrial engineering, Payam Noor University in Tehran, Iran. $\mathrm{He}$ is a member of young researcher and elite club of Islamic Azad University. His research interests include multi criteria decision making and supply chain network design.

Seyed Meysam Mousavi is an Associate Professor at the Department of Industrial Engineering, Faculty of Engineering, Shahed University in Tehran, Iran. He received his $\mathrm{PhD}$ from the School of Industrial Engineering at University of Tehran, Iran and is currently a member of Iran's National Elite Foundation. He is the Head of the Industrial Engineering Department at Shahed University. His main research interests include cross-docking systems planning, quantitative methods in project management, logistics planning and scheduling, multiple criteria decision-making under uncertainty and applied soft computing. He has published many papers and book chapters in reputable journals and international conference proceedings. 